
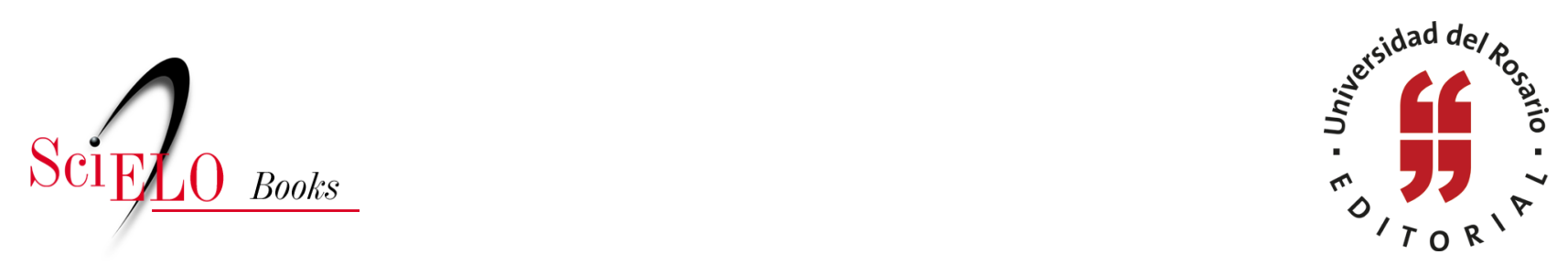

\title{
Capítulo primero \\ Exclusión probatoria por injerencias al derecho a la intimidad en el derecho colombiano
}

\author{
Joel M. F. Ramírez-Mendoza
}

\section{SciELO Books / SciELO Livros / SciELO Libros}

RAMÍREZ MENDONZA, J.M.F. Exclusión probatoria por injerencias al derecho a la intimidad en el derecho colombiano. In: Diferencias entre las reglas de exclusión probatoria colombiana e internacional penal. Análisis en tres casos de injerencias en comunicaciones privadas [online]. Bogotá: Editorial Universidad del Rosario, 2015, pp. 35-102. Opera prima collection. ISBN: 978-958738-658-5. https://doi.org/10.7476/9789587386585.0002.

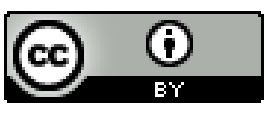

All the contents of this work, except where otherwise noted, is licensed under a Creative Commons Attribution 4.0 International license.

Todo o conteúdo deste trabalho, exceto quando houver ressalva, é publicado sob a licença Creative Commons Atribição 4.0.

Todo el contenido de esta obra, excepto donde se indique lo contrario, está bajo licencia de la licencia $\underline{\text { Creative }}$ Commons Reconocimento 4.0 . 


\section{Capítulo primero \\ Exclusión probatoria por injerencias \\ al derecho a la intimidad en el derecho colombiano}

\section{Introducción}

Este capítulo tiene por fin describir el marco del derecho a la intimidad y su relación con el debido proceso. Después nos concentraremos en el proceso penal colombiano, principalmente con las interceptaciones de comunicaciones, y la regla de exclusión. Finalmente, expondremos tres casos que se presentaron en el sistema nacional colombiano, los que muestran una tensión de estos con el marco previamente construido.

\subsection{Derecho a la intimidad y su relación con la interceptación de comunicaciones}

1.1.1 Fundamentos de protección de la intimidad como expresión de la dignidad humana

La actual forma de organización política de Colombia es la del Estado social de derecho. Esto hace que se adicionen al Estado de derecho los tres siguientes componentes: 
(1) La dimensión de la vinculación Social del Estado, que implica la obligación de los poderes públicos de velar por la previsión, distribución e igualación de los bienes materiales y de cultura; (2) La dimensión de la referencia social de los derechos fundamentales, que impone la obligación de interpretar estos derechos, desde el principio de garantía de la libertad; (3) La dimensión de la obligación del Estado de articular la sociedad desde bases democráticas ${ }^{1}$ (numerales fuera de texto original).

También se entiende por Estado social de derecho aquel "[e]stado construido sobre un principio estructural complejo, por ser principio de principios, cuya esencia radica en que su contenido y alcance deriva de la recíproca interacción de los valores de la democracia, lo social y la idea del Estado de Derecho en sentido material". ${ }^{2}$

Desde este punto de vista, el Estado se funda en el respeto de la dignidad humana, entendido según el segundo imperativo categórico de Kant: "Obra de tal modo que uses la humanidad, tanto en tu persona como en la persona de cualquier otro, siempre como un fin al mismo tiempo y nunca solamente como un medio". ${ }^{3}$ Sobre esto la Corte Constitucional dice que "La dignidad humana es el valor

1 Quinche Ramírez, Manuel Fernando. Derecho Constitucional Colombiano: de la Carta de 1991 y sus reformas. 5. ${ }^{a}$ ed., Editorial Temis, Bogotá, 2008, p. 49.

2 Ibíd., p. 49, citando a: Parejo, Luciano. Estado social y administración pública. Editorial Civitas, Madrid, 1983.

3 Corte Constitucional, Sentencia T-211 de 1994, citando a: Kant, Inma- 
supremo del Estado Social de Derecho". ${ }^{4}$ Asimismo, tanto la Corte Suprema de Justicia, Sala de Casación Penal, como la Corte Constitucional han entendido que la dignidad humana es uno de los pilares del Estado colombiano y se ha entendido en tres aspectos: “(i) es un principio fundante del ordenamiento jurídico y en este sentido tiene una dimensión axiológica como valor constitucional, (ii) es un principio constitucional y (iii) tiene el carácter de derecho fundamental autónomo". 5

Entender a una persona como un fin en sí mismo implica también que la persona es libre, es decir, que tiene la capacidad de autogobernarse, ${ }^{6}$ indica que la dignidad se relaciona directamente con la libertad de la persona. Tanto la libertad como la dignidad son consideradas como principios constitucionales, entendiendo "principios" como "normas que [ordenan] algo [y que] sea realizado en la mayor medida posible dentro de las posibilidades jurídicas y reales existentes; [p]or mandatos de optimización, que están ca-

nuel. Fundamentos de la metafísica de las costumbres. Edit. Porrúa S.A., México, 1990, pág. 44.

4 Quinche Ramírez, Manuel Fernando. Op. cit., p. 75, citando a: Corte Constitucional, Sentencia C-414 de 1992.

5 Corte Suprema de Justicia-Sala de Casación Penal, Sentencia Rad. 33.621, Sentencia de 10 de marzo de 2010, citando Corte Constitucional, Sentencia C-355 de 2006. Ver Corte Constitucional, Sentencia T-881 de 2002, en la cual se hace un exhaustivo recuento de los alcances funcionales y normativos del concepto dignidad humana.

6 Rojas Gómez, Miguel Enrique. Eficacia de la prueba obtenida mediante irrupción en la intimidad. Universidad Externado de Colombia, Bogotá, 2011, p. 28. 
racterizados por el hecho de que pueden ser cumplidos en diferente grado". 7 Además, son "normas que condicionan las demás normas, pero con mayor grado de concreción y por lo tanto de eficacia, alcanzando por sí mismo proyección normativa", precisando que son "dotadas de toda fuerza normativa, de aplicación inmediata, tanto por el legislador como por el juez". ' Por ello "[e]l sujeto razón y fin de la Constitución de 1991 es la persona humana, no es pues el individuo en abstracto, aisladamente considerado, sino precisamente el ser humano en su dimensión social, visto en la tensión individuo-comunidad, la razón última de la nueva carta Política" ${ }^{10}$ Estos principios irradian el art. 1. ${ }^{\circ}$ del Código Penal vigente que dice: "El derecho penal tendrá como fundamento el respeto a la dignidad humana”. De igual forma en el art. $1^{\circ}$ del Código de Procedimiento Penal, Ley 906, dice: "Los intervinientes en el proceso penal serán tratados con el respeto debido a la dignidad humana".

El derecho a la intimidad, reconocido en el art. 15 constitucional, se encuentra relacionado precisamente con el principio de dignidad, siendo este base para el tipo de Estado vigente. La Corte Constitucional, siguiendo a Schneider, afirma que "el Estado debe 'asegurar' a la persona un ámbito de libertad en el que desarrolle espontáneamente su

7 Quinche Ramírez, Manuel Fernando. Op. cit., p. 64, citando a: Alexy, Robert. Teoría de los derechos fundamentales. Centro de Estudios Constitucionales, Madrid, 1983.

8 Ibíd., p. 68, citando a: Corte Constitucional, Sentencia C-1287 de 2001.

9 Ibíd., p. 68.

10 Corte Constitucional, Sentencia T-011 de 1992. 
personalidad y en el que podrán refugiarse discreta e incontroladamente y donde gozarán el derecho a la 'intimidad', expresión de su dignidad humana”. ${ }^{11}$ Esa relación se da porque una vigilancia no deseada impide a la persona realizar todas aquellas conductas que realizaría en su intimidad o privacidad. ${ }^{12}$ En este orden de ideas, la intimidad tiene una relación directa con la libertad y la dignidad de la persona, y por tanto se puede identificar como un valor y un principio constitucional que irradia otras normas jurídicas.

Hay diferentes formas de proteger derechos o principios constitucionales; uno de los medios para ello es tratarlos como bienes jurídicos, como es el caso del derecho a la intimidad. Por ello el legislador decide protegerlos a partir del desarrollo normativo penal en diferentes formas, no solo a través de la consagración de tipos penales, sino también con la regulación de la cláusula o regla de exclusión de la prueba obtenida con violación de este derecho. ${ }^{13} \mathrm{Un}$ caso de lo anterior es lo relacionado con la interceptación de comunicaciones; esta se encuentra regulada como tipo penal en el art. 169 del Código de Penal (CP) con el nombre "violación ilícita de comunicaciones". Adicionalmente,

11 Corte Constitucional, Sentencia T-011 de 1992, citando a: Schneider, Hans Peter. Democracia y Constitución. Centro de Estudios Constitucionales, Madrid, 1991, p. 21; Cfr., Corte Constitucional, Sentencia T-414 de 1992.

12 Rojas Gómez, Miguel Enrique. Op. cit., pp. 29, 30.

13 Cfr., Von Hirsh, Andrew. El concepto de bien jurídico y el "principio de daño". En: Hefendehl, Roland (Edit.). La teoría del bien jurídico. ¿Fundamento de legitimación de derecho penal o juego de abolorios dogmático? Editorial Marcial Pons, Madrid, 2007. 
encontramos la regulación para la producción de la prueba en el Código de Procedimiento Penal (CPP) en el art. 235, de manera que si la interceptación no está en regla con este artículo, se ordena la exclusión probatoria en cumplimiento del art. 23 del mismo. Vemos entonces cómo el derecho a la intimidad, en estos casos, se puede ver como bien jurídico tutelable que se protege a partir de la configuración de tipos penales, pero también con la inadmisibilidad, o en su defecto la exclusión, de material probatorio que se produjo a partir de la injerencia indebida en la intimidad de las personas.

La relación que hay entre el proceso penal y la dignidad humana se concreta en un punto preciso: el afán por obtener la verdad real o sustancial. Como bien dice Urbano Martínez: "[e]n tal contexto, la búsqueda de la verdad histórica dentro de un proceso, si bien sigue siendo el presupuesto para la emisión de una decisión justa, ya no es algo que se puede conseguir a cualquier precio, pues en su búsqueda se deben respetar unas barreras que al poder político le resultan infranqueables"14. Este es un punto que se viene desarrollando desde 1906 por Ernst Beling cuando dice: "Habrá completo acuerdo acerca del principio de que también el proceso penal debe respetar la dignidad humana y en consecuencia un conflicto insoluble entre la dignidad

14 Urbano Martínez, José Joaquín. Prueba ilícita y regla de exclusión. En: Uprimny, Rodrigo y otros. Reflexiones sobre el nuevo sistema procesal penal. Instituto de Estudios del Ministerio Público. 2. ${ }^{a}$ ed, Bogotá, 2006, p. 269. 
humana e intereses del proceso penal tiene que conllevar una prohibición probatoria". ${ }^{15}$

\subsubsection{La protección de las comunicaciones} como una manifestación del derecho a la intimidad Partimos del significado de la palabra "intimidad": la Real Academia de la Lengua Española la entiende, en su segunda acepción, como la " [z]ona espiritual íntima y reservada de una persona o de un grupo, especialmente de una familia". ${ }^{16}$ El derecho a la intimidad se relaciona con la privacidad de la persona, y esta se entiende como "[á]mbito de la vida privada que se tiene derecho a proteger de cualquier intromisión" ${ }^{17}$ Siendo así, entendemos la intimidad como el espacio donde se desarrolla la vida privada, ya sea de una persona o un grupo, y por tanto es de carácter reservado y libre de intromisión alguna.

Dentro del marco nacional, el derecho a la intimidad lo encontramos expresamente en el art. 15. Este reza:

Artículo 15. Todas las personas tienen derecho a su intimidad personal y familiar y a su buen nombre, y el Estado debe respetarlos y hacerlos respetar. De igual

15 Beling, Ernst. Las probibiciones de prueba como límite a la averiguación de la verdad en el proceso penal. En: Beling, Ernst y otros. Las probibiciones probatorias. Editorial Temis S.A, Bogotá, 2009, p. 52.

16 Diccionario de la Real Academia de la Lengua Española, revisado el 4 de agosto de 2013, en: http://lema.rae.es/drae/?val=intimidad.

17 Diccionario de la Real Academia de la Lengua Española, revisado el 4 de agosto de 2013, en: http://lema.rae.es/drae/?val=privacidad. 
modo, tienen derecho a conocer, actualizar y rectificar las informaciones que se hayan recogido sobre ellas en bancos de datos y en archivos de entidades públicas y privadas.

En la recolección, tratamiento y circulación de datos se respetarán la libertad y demás garantías consagradas en la Constitución.

La correspondencia y demás formas de comunicación privada son inviolables. Sólo pueden ser interceptadas o registradas mediante orden judicial, en los casos y con las formalidades que establezca la ley.

Para efectos tributarios o judiciales y para los casos de inspección, vigilancia e intervención del Estado podrá exigirse la presentación de libros de contabilidad y demás documentos privados, en los términos que señale la ley ${ }^{18}$ (cursivas fuera del texto).

Este derecho si bien tiene una primera manifestación en la Primera Enmienda a la Constitución de los Estados Unidos cuando trata el derecho a la intimidad religiosa, el derecho a la intimidad como tal "adquiere identidad definitiva en 1890, en los Estados Unidos, cuando Warren y Brandeis elaboran el 'Right of Privacity'; posteriormente en fallo de 1965 de la Corte Suprema de los Estados Unidos, en el caso Griswald vs. Connecticut, le confiere los alcances definitivos

18 República de Colombia, Constitución Política de Colombia, publicada en Gaceta Constitucional n. ${ }^{\circ} 116$ de 20 de julio de 1991, art. 15. 
que actualmente posee este derecho". ${ }^{19}$ Basándose en esto, la Corte Constitucional colombiana adopta y desarrolla la dicotomía entre lo "público" y lo "privado". 20

Esta norma no es nueva en el sistema jurídico nacional. La prohibición estaba regulada en el art. 59-1 de la Constitución de 1858, en el art. 15 de la Constitución de 1863, y en la Carta de 1886, en su art. 38. ${ }^{21}$ Actualmente, la Corte Constitucional entiende que "La vida privada, al sentir de Novoa Monreal, 'está constituida por aquellos fenómenos, comportamientos, datos y situaciones de una persona que normalmente están sustraídos al conocimiento de extraños y cuyo conocimiento por éstos puede turbarla moralmente por afectar su pudor o su recato a menos que esa misma persona asienta a ese conocimiento"'.22 Con ello, se entiende por intimidad personal el "área restringida inherente a toda persona o familia, que solamente puede ser penetrada por extraños con el consentimiento de su titular o mediando orden dictada por autoridad competente, en ejercicio de sus funciones y de conformidad con la Constitución y la ley". ${ }^{23}$ Es importante distinguir que la Constitución vigen-

19 Corte Constitucional, Sentencia T-011 de 1992; Cfr., Escobar López, Édgar; Marulanda Otálvaro, Luz Fabiola. El derecho a la Intimidad. 2. a ed, Ediciones Doctrina y Ley, Bogotá, 2004.

20 Corte Constitucional, Sentencia T-787 de 2004.

21 Corte Constitucional, Sentencia T-349 de 1993.

22 Corte Constitucional, Sentencia T-011 de 1992, citando a: Novoa Monreal, Eduardo. Derecho a la vida privada y libertad de información. Un conflicto de derechos. Ediciones Siglo XXI, México, 1989, p. 87 y ss; Cfr., Corte Constitucional, T-787 de 2004.

23 Corte Constitucional, Sentencia T-233 de 2007, citando a: Corte 
te abarca diferentes rangos de intimidad, como es el caso de la inviolabilidad del domicilio en el art. 28, registros de información personal, es decir el habeas data en el art. 15 inc. 1 , y la prohibición de interceptación de comunicaciones en el inciso 2 del mismo artículo. Siendo así, en ellos nos concentraremos en la interceptación de comunicaciones.

Édgar Escobar López y Luz Fabiola Marulanda entienden que el derecho a la intimidad está compuesto por tres aspectos: la tranquilidad, la autonomía y el control de información. ${ }^{24}$ La tranquilidad de la persona se entiende - citando a Novoa Montreal - como "el derecho que tiene todo ser humano a disponer de momentos de soledad, recogimiento y quietud que le permite replegarse sobre sí mismo". 25 En relación con la autonomía, "[e]l derecho al respeto de la vida privada consiste esencialmente en poder conducir su

Constitucional, Sentencia T-696 de 1996; Cfr., Corte Constitucional, Sentencia T-787 de 2004 al decir: "el núcleo esencial del derecho a la intimidad, supone la existencia y goce de una órbita reservada en cada persona, exenta del poder de intervención del Estado o de las intromisiones arbitrarias de la sociedad, que le permita a dicho individuo el pleno desarrollo de su vida personal, espiritual y cultural"; Cfr., CIDH, Caso Escher y otros v. Brasil. Sentencia de 6 de julio de 2009, párr. 113; y Caso Tristán Donoso v. Panamá. Sentencia de 27 de enero de 2009, párr. 55; Naciones Unidas, Comité de Derechos Humanos, Observación General n. ${ }^{\circ}$ 16, Article 17 (The right to respect of privacy, family, home and correspondence, and protection of honour and reputation) HRI/GEN/1/Rev.7 at 162 de 28 de septiembre de 1988, párr. 3.

${ }^{24}$ Escobar López, Édgar y Marulanda Otálvaro, Luz Fabiola. Op. cit., p. 39.

25 Ibíd., p. 39, citando a: Novoa Montreal, Eduardo. Derecho a la vida privada y libertad de información. Un conflicto de intereses. Ediciones Siglo XXI, México, p. 96. 
vida como uno pretenda, con un mínimo de injerencias". ${ }^{26} \mathrm{Y}$ el tercer aspecto, el control de información, "[l]a Intimidad o privacidad, con respecto a la información, se manifiesta en dos direcciones: una, la posibilidad de mantener ocultos o reservados ciertos aspectos de la vida de las personas; de otro lado, la posibilidad que corresponde a cada individuo controlar el manejo y circulación que sobre su persona ha sido confiada a un tercero". ${ }^{27}$

De igual forma, el profesor Rojas Gómez reconoce tres áreas por las cuales el derecho a la intimidad termina siendo susceptible de protección: "[1] ocultabilidad material en el respectivo contexto, [2] voluntad de preservación respecto del conocimiento ajeno, e [3] idoneidad de las precauciones para asegurar el ocultamiento". ${ }^{28}$ La primera consiste en elementos propios de la persona cuyo ocultamiento dificultaría su identificación, como su rostro o su nombre, pero hay aspectos que sí son protegidos por esta calificación como es el caso de su sexualidad, creencias religiosas o pensamientos, acorde con los arts. 18 y 19 de la Constitución, por tanto aquí es importante la relación del sujeto con el contexto en general; en el caso de la correspondencia postal, por ejemplo, resulta imposible ocultar información como los datos del remitente y de destinatario, pero la información del conte-

26 Ibíd., p. 40, citando a: "Resolución 428 de la Asamblea Consultiva del Consejo de Europa (sic)".

27 Ibíd., p. 40, citando a: Ferreira Rubio, Delia Matilde. El derecho a la intimidad. Editorial Universidad, Buenos Aires, 1982.

28 Rojas Gómez, Miguel Enrique. Op. cit., p. 37. 
nido de la carta sí es protegida. ${ }^{29} \mathrm{La}$ segunda consiste en la voluntad de mantener reservado un conocimiento ajeno; es la decisión de la persona de guardar un secreto o exhibirlo al público; ${ }^{30}$ habría problema cuando lo exhibe teniendo cláusula de confidencialidad o en el caso de un interrogatorio en un proceso judicial: con relación a la protección de guardar un secreto, encontramos los límites al deber de declarar en el art. 33 de la Carta Política. La tercera área consiste en que "lo íntimo sólo puede ser protegido como tal en cuanto se realice o se conserve de manera idónea para asegurar el ocultamiento"31; si bien el ejemplo que expone el autor es la evacuación de desechos corporales en lugares públicos, posteriormente trata la comunicación entre personas, protegida por el derecho en el ya señalado art. 15.

Hay que tener en cuenta que Rojas Gómez diferencia la privacidad individual y la privacidad intersubjetiva. En concreto, la diferencia radica en que una expresión del derecho a la intimidad, como es el caso de exámenes de ADN (art. 245, CPP) es individual, y es diferente cuando se trata de una interceptación de comunicaciones (art. 235, CPP), que es interpersonal. ${ }^{32}$ Concentrándonos en nuestra materia, cuando una persona decide comunicarse con otra, en ejercicio de su libertad, la persona escoge qué, cómo, cuándo y a quién transmitir un mensaje. Una obstrucción a esto sería

\footnotetext{
29 Ibíd., pp. 27-28.

30 Ibíd., p. 38.

31 Ídem.

32 Ibíd., pp. 81-112.
} 
una restricción a la libertad de la persona. Ahora, cuando una persona realiza una de esas actividades de forma pública ya no le correspondería la protección del derecho a la intimidad. ${ }^{33}$ Por esa razón se estudia la idoneidad del medio en que se da el mensaje y la voluntad de la persona de mantenerlo en secreto; esta información es cobijada por el art. 15 constitucional por ser considerada una "comunicación privada" y tiene una relación directa con el control de la información, como señalan Escobar López y Marulanda Otálvaro.

Concentrándonos en el tercer grupo que señalan estos dos profesores, y en relación con la calificación que presenta el profesor Rojas Gómez, la comunicación privada debe ser idónea para poder mantener el control de la información, sin olvidar que corresponde a una intimidad intersubjetiva. Sin embargo, hay una relación entre vida privada e información oficial, y la forma en que se relacionan estas dos termina creando los supuestos básicos de la relación Persona-Estado ${ }^{34}$. Precisamente en este punto, el art. 15 inc. 3 constitucional reza: "Sólo pueden ser interceptadas o registradas mediante orden judicial, en los casos y con las formalidades que establezca la ley", teniendo en cuenta que el Estado también tiene el deber de proteger a las personas y sus bienes según su art. 2, siendo este el fundamento para una investigación penal y para desarrollar actividades para mantener la seguridad nacional. De tal manera podemos deducir que sí se pueden hacer intromisiones, siempre y

33 Ibíd., p. 72.

34 Corte Constitucional, Sentencia T-011 de 1992. 
cuando el punto se encuentre regulado en una ley y se obtenga una orden judicial. ${ }^{35}$

La Corte Constitucional ha venido haciendo una clasificación de tipos de información, donde se distinguen los siguientes tipos: información pública, que puede ser obtenida sin reserva o impedimento alguno; información semiprivada, la que solo se puede conseguir a partir de una orden de una autoridad administrativa; información privada, que solamente se obtiene por orden judicial; e información reservada, que no se puede obtener, ni siquiera con autoridad judicial, en la que "[c]abría mencionar aquí la información genética, y los llamados 'datos sensibles' ${ }^{36}$ o relacionados con la ideología, la inclinación sexual, los hábitos de la persona, etc". ${ }^{37}$ De igual forma, la Corte diferencia entre información impersonal y personal, haciendo claridad que el art. 15 constitucional protege la información personal. ${ }^{38} \mathrm{Si}$ bien la clasificación puede ser etérea al momento de concretarla en un caso, sirve para resaltar la importancia de distinguir de qué tipo de información se está discutiendo, más aun cuando

35 Cfr., T-349 de 1993; y cidH. Caso Escher y otros v. Brasil. Sentencia del 6 de julio de 2009, párr. 116; CIDH, Caso Tristán Donoso v. Panamá. Sentencia de 27 de enero de 2009, párrs. 56, 58; Naciones Unidas, Comité de Derechos Humanos, Observación General n. ${ }^{\circ} 16$-Article 17 (The right to respect of priva$c y$, family, home and correspondence, and protection of honour and reputation) HRI/GEN/1/Rev.7 at 162 de 28 de septiembre de 1988, párr. 4.

Corte Constitucional, Sentencia T-011 de 1992.

36 Corte Constitucional, Sentencia T-729 de 2002, citando a: Sentencia T-307 de 1999.

37 Corte Constitucional, Sentencia T-729 de 2002.

38 Ídem. 
se pueden encontrar diferentes grados de intimidad, no solo el personal sino también el familiar, social, o el gremial ${ }^{39}$ (todas estas de carácter intersubjetivo); y además se debe estudiar el alcance de la comunicación "privada", en cuanto que puede comprenderse entre lo semiprivado y reservado.

Retomando la relación Persona-Estado, la Corte Constitucional considera que "[e]l Estado debe conocer lo mínimo necesario para que la persona viva en el contexto social gozando del máximo espacio vital a que tiene derecho para lograr el desarrollo de la personalidad". ${ }^{40}$ Por tanto, la regla general es que hay una prevalencia del derecho a la intimidad sobre el acceso a la información. ${ }^{41}$

En los casos de la interceptación de comunicaciones, hay un efecto en todos estos aspectos del derecho a la intimidad. La jurisprudencia constitucional ha establecido que:

El secreto de las comunicaciones, garantizado por el precepto constitucional en cita, es considerado por la doctrina como un derecho individual resultado del status

39 Corte Constitucional, Sentencia T-787 de 2004.

40 Corte Constitucional, Sentencia T-011 de 1992, citando a: Schneider, Hans Peter. Democracia y Constitución. Centro de Estudios Constitucionales, Madrid, 1991, p. 21. Cfr., Corte Constitucional, Sentencia T-787 de 2004, dice: salvo las excepciones previstas en la Constitución y la ley, que obliguen a las personas a revelar cierta información a partir de su reconocimiento o valoración como de importancia o relevancia pública; el resto de los datos que correspondan al dominio personal de un sujeto no pueden ser divulgados, a menos que el mismo individuo decida revelar autónomamente su acceso al público.

41 Corte Constitucional, Sentencia T-414 de 1992. 
libertatis de la persona, que, como ya se dijo, garantiza a ésta un espacio inviolable de libertad y privacidad frente a su familia, a la sociedad y al Estado. La inviolabilidad de la correspondencia es apreciada en cuanto preserva el derecho de la persona al dominio de sus propios asuntos e intereses, aún los intranscendentes, libre de la injerencia de los demás miembros de la colectividad $y$, especialmente, de quienes ejercen el poder público. ${ }^{42}$

Como la regla general es la prevalencia del derecho a la intimidad sobre la información, para que haya una injerencia por parte del Estado se requiere que haya una orden judicial dentro de las formalidades y requisitos legales. La Corte Interamericana de Derechos Humanos (CIDH) entiende que "la protección a la vida privada se concreta en el derecho a que sujetos distintos de los interlocutores no conozcan ilícitamente el contenido de las conversaciones telefónicas o de otros aspectos, como los ya mencionados, propios del proceso de comunicación". ${ }^{43}$ Dicho de otra forma, la injerencia que cumpla con los requisitos legales y con la autorización legal será lícita.

Sin embargo, como ha venido explicando la Corte Suprema de Justicia, lo que se prohíbe es la interceptación ajena, de tal manera que una persona puede interceptar su propia línea telefónica, grabar la conversación, e incluso solicitar

42 Corte Constitucional, Sentencia T-349 de 1993.

43 CIDH, Caso Escher y otros v. Brasil. Sentencia del 6 de julio de 2009, párr. 114. 
a la autoridad judicial competente que lo haga, dado que es su propia voluntad la que decide hacerla. ${ }^{44}$ Por tanto, no se necesita de autorización judicial cuando la víctima permite a la policía judicial hacer la interceptación. ${ }^{45}$ Ahora, Rojas Gómez considera que la potestad de interceptar y grabar la conversación es de cualquiera de las personas que estén en dicha conversación. ${ }^{46}$

44 Corte Suprema de Justicia-Sala de Casación Penal, Rad. 9579, Sentencia de 22 de octubre de 1996, citando Corte Suprema de Justicia-Sala de Casación Penal, Sentencia de 16 de marzo de 1988, M.P. Martínez Zúñiga. Este dice:

Por ello conviene advertir que cuando no se trate de grabar la propia voz, o recoger documentalmente la propia imagen, ni de interceptar la línea telefónica que se tiene, sino de registrar comunicaciones o imágenes privadas de otras personas, es necesario que se obre en cumplimiento de una orden emanada de autoridad judicial competente, en cuanto ello implica invadir la órbita de intimidad personal ajena, también protegida como derecho constitucional fundamental (art. 15), como se dejó dicho.

Cfr., Corte Suprema de Justicia-Sala de Casación Penal, Rad. 13.948, Sentencia de 30 de noviembre de 200; Rad. 21.216 de 6 de agosto de 2003; Rad. 10.656 del 24 de noviembre de 2004; y Rad. 24.679 del 27 de julio de 2006.

45 Cfr., Corte Suprema de Justicia-Sala de Casación Penal, Rad. 13.148, Sentencia de 21 de noviembre de 2002; y Corte Suprema de Justicia-Sala de Casación Penal, Rad. 24.679, Sentencia de 27 de julio de 2006:

La Sala precisa en este caso que salvo cuando se requiera autorización judicial, la grabación, interceptación de la voz o la filmación de imágenes, será viable jurídicamente (con capacidad para servir como medio de prueba judicial) cuando exista o se exprese el consentimiento de todos quienes intervienen en la conversación o en el acto que es objeto de filmación o grabación, predicándose como excepción a lo afirmado aquel evento ya insistentemente desarrollado por la jurisprudencia - que hoy se reiterarelativo a la preconstitución de prueba cuando se es víctima de un delito y la obtención de la respectiva información comporta fines judiciales probatorios.

46 Rojas Gómez, Miguel Enrique. Op. cit., pp. 50, 51, 89. 


\subsubsection{Excepción: el derecho a la intimidad cede ante el derecho a la información por autorización judicial}

La Convención Americana de Derechos Humanos (CADH) y el Pacto Internacional de Derechos Civiles y Políticos (PIDCP) tienen dos puntos en común: primero, que las injerencias no deben ser arbitrarias, y segundo, la ley necesariamente tiene el deber de proteger la intimidad. La autorización judicial revisa de manera precisa el cumplimiento del ordenamiento interno; la autorización debe ser razonada y ponderada de acuerdo con la situación concreta, con la carga de preferir la protección al derecho a la intimidad. ${ }^{47}$ Ante esto la Corte Constitucional ha expuesto tres requisitos para que se dé dicha autorización: "1. Que medie orden judicial; 2. Que se presente alguno de los casos establecidos en la ley; 3. Que se cumplan las formalidades señaladas en la ley". ${ }^{48}$ Aunque en este caso la Corte habla expresamente de correspondencia, la regla se extiende a todas las formas de

47 Cfr., CidH. Caso Escher y otros v. Brasil. Sentencia del 6 de julio de 2009, párr. 116; Caso Tristán Donoso v. Panamá, Sentencia de 27 de enero de 2009, párrs. 56, 58; Naciones Unidas, Comité de Derechos Humanos, Observación General n. ${ }^{\circ}$ 16-Article 17 (The right to respect of privacy, family, home and correspondence, and protection of honour and reputation), HRI/GEN/1/ Rev.7 at 162 de 28 de septiembre de 1988, párr. 4.

48 Corte Constitucional, Sentencia T-349 de 1993; Cfr., Corte Constitucional, Sentencia C-657 de 1996, Sentencia T-696 de 1996; y Cfr., cidH. Caso Escher y otros v. Brasil. Sentencia del 6 de Julio de 2009, párrs. 129, 168. Esta última dice: "Como ya se indicó, para que resulte conforme a la Convención Americana una injerencia debe cumplir con los siguientes requisitos: a) estar prevista en ley; b) perseguir un fin legítimo, y c) ser idónea, necesaria y proporcional. En consecuencia, la falta de alguno de dichos requisitos implica que la injerencia es contraria a la Convención". 
comunicación. ${ }^{49}$ Por el avance tecnológico, la interceptación de correspondencia escrita ha perdido impacto; sin embargo, se ha venido expandiendo a otros sistemas de comunicación, como son el teléfono celular e Internet. ${ }^{50}$

Es importante resaltar que técnicamente interceptar consiste en apoderarse de, interrumpir, u obstruir una comunicación; mientras que registrar es examinar con cuidado el contenido de dicha comunicación. ${ }^{51}$ Cualquiera de las dos acciones es violación al derecho a la intimidad, independientemente del medio o método con que se haya hecho. ${ }^{52}$ Es muy común encontrar que, tanto legal como jurisprudencialmente, se entienda por interceptar los dos conceptos expuestos. Esto se debe a que originalmente se estaba enfocado en la correspondencia, por tanto era posible hacer la distinción; sin embargo, por ese desarrollo tecnológico, estos dos se han terminado mezclando en un mismo momento. Adicionalmente encontramos la acción de grabar, dado que muchas veces no basta con escuchar la conversación, sino también se hace la grabación de la misma. Ante esto la Corte ha dicho:

En esa medida, las grabaciones de imagen o de voz realizadas en ámbitos privados de la persona, con destino a

49 Cfr., Corte Constitucional, Sentencia C-131 de 2009.

50 Cfr., Fierro Méndez, Heliodoro. Prueba ilícita. Interceptación de comunicaciones y registro de computadores. Ediciones Doctrina y Ley, Bogotá, 2012, títulos primero y segundo.

51 Cfr., Corte Constitucional, Sentencia T-696 de 1996.

52 Cfr., Ídem. 
ser publicadas o sin ese propósito, constituyen violación del derecho a la intimidad personal, si las mismas no han sido autorizadas directamente por el titular del derecho y, además, en caso extremo, si no han sido autorizadas expresa y previamente por autoridad judicial competente. El resultado de la recolección de la imagen o la voz sin la debida autorización del titular implica, sin más, el quebrantamiento de su órbita de privacidad y, por tanto, la vulneración del derecho a la intimidad del sujeto. ${ }^{53}$

Siendo así, hay que tener en cuenta que el proceso de una interceptación como se la entiende generalmente comprende a tres acciones: primero, interceptar propiamente dicho; ${ }^{54}$ segundo, grabar en ámbitos de la comunicación; y tercero, ya grabada, registrar la información. Hay que tener en cuenta que la interceptación de comunicaciones solo le es permitida a las entidades públicas, principalmente a la Policía Judicial, y solamente con orden judicial como establece la Constitución, por lo que le está prohibido a las entidades privadas y a las entidades públicas que no tengan esta competencia. La jurisprudencia ha establecido que:

La Corte Constitucional, en guarda de la cabal interpretación y aplicación de las normas constitucionales enunciadas y de los tratados internacionales sobre de-

53 Corte Constitucional, Sentencia T-233 de 2007.

54 Una descripción del procedimiento de interceptaciones en concreto, la encontramos en Fierro Méndez Heliodoro. Op. cit., título segundo. 
rechos humanos, que han sido estrictos y celosos en la materia (Cfr. Convención Americana sobre Derechos Humanos, "Pacto de San José de Costa Rica”, aprobada mediante Ley 16 de 1992, artículo 11; Pacto Internacional de Derechos Civiles y Políticos, aprobado por Ley 78 de 1968, artículo 17), debe declarar sin ambages que ninguna persona pública ni privada, por plausible o encomiable que sea el objetivo perseguido, está autorizada para interceptar, escuchar, grabar, difundir ni transcribir las comunicaciones privadas, esto es, las que tienen lugar entre las personas mediante conversación directa, o por la transmisión o registro de mensajes, merced a la utilización de medios técnicos o electrónicos aptos para ello, tales como teléfonos convencionales o celulares, radioteléfonos, citófonos, buscapersonas, equipos de radiocomunicaciones, entre otros, A MENOS QUE EXISTA PREVIA Y ESPECIFICA ORDEN JUDICIAL Y QUE ELLA SE HAYA IMPARTIDO EN EL CURSO DE PROCESOS, EN LOS CASOS Y CON LAS FORMALIDADES QUE ESTABLEZCA LA LEY, según los perentorios términos del artículo 15 de la Constitución Política ${ }^{55}$ (mayúsculas hacen parte del texto original; cursivas fuera del texto).

Por lo anterior, encontramos que la regla general es que no se pueda hacer interceptación de comunicaciones privadas, a menos que haya una orden judicial que lo permita,

55 Corte Constitucional, Sentencia C-626 de 1996; Cfr., Corte Constitucional, sentencias C-382 de 1996, T-233 de 2007 y C-131 de 2009. 
teniendo en cuanta que aun así hay una carga a favor del derecho a la intimidad en cuanto es una manifestación de la dignidad humana. Dicha interceptación solo podrán hacerla aquellas autoridades públicas que tengan esa función, y debe estar sujeta a lo reglamentado por la ley, dentro de un debido proceso y bajo la protección del bien jurídico tutelado penalmente. Por tanto, entramos a estudiar y precisar el debido proceso penal en general, y la interceptación en particular.

\subsection{Derecho al debido proceso y su relación con el derecho a la intimidad}

Entendemos el debido proceso como "el conjunto de garantías previstas en el ordenamiento jurídico, a través de las cuales se busca la protección del individuo incurso en una actuación judicial o administrativa, para que durante su trámite se respeten sus derechos y se logre la aplicación correcta de la justicia". ${ }^{56}$ Por tal razón el proceso penal, con el intento de ser metódico y lógico, construye una relación entre Ius Puniendi del Estado por un lado, y por el otro el derecho de la defensa de la persona, en el que se busca garantizar sus derechos. ${ }^{57}$

Así las cosas, describiremos someramente el proceso penal de modo general para tener claro el marco de legalidad en el que se debe producir la debida autorización para esas intervenciones, y luego se explicará la forma en que se

56 Corte Constitucional, Sentencia C-980 de 2010.

57 Cfr., Corte Constitucional, Sentencia C-782 de 2005. 
introduce la interceptación de comunicaciones, con algunos comentarios relacionados a este tema sobre las actividades de inteligencia. Seguidamente entramos a estudiar la regla de exclusión, siendo esta una garantía de protección en casos de violación al derecho a la intimidad, y terminamos revisando dentro de ese marco de legalidad los tres casos escogidos de referencia en cuanto a la interceptación de comunicaciones.

\subsubsection{Breve descripción de los procesos penales en Colombia}

\subsubsection{Sistemas procesales antecesores a la Ley 906 de 2004}

Antes del Acto Legislativo 03 de 2002 y de la Ley 906 de 2004 se manejaba un sistema judicial con indudables rasgos inquisitivos, donde la Fiscalía era una autoridad judicial. En el último de esos códigos de procedimiento penal, en el contexto del Decreto 2700 de 1991, había un control sobre las interceptaciones de comunicaciones, según el art. 351, en el que si la solicitud para realizar la interceptación provenía del fiscal delegado, se requería autorización por parte de la Dirección Nacional de Fiscalías, en consonancia con el art. 35.5 del Decreto 2699 de 1991, anterior Estatuto Orgánico de la Fiscalía. Esta situación procedía en la etapa de instrucción. Pero si la iniciativa surgía de la Policía Judicial, se regía por el art. 47 del Decreto 2699, se requería la autorización del fiscal encargado, lo que se daba en la investigación previa. ${ }^{58}$ Esta

58 Cfr., Corte Suprema de Justicia-Sala de Casación Penal, Rad. 9.579, 
forma de control buscaba que "al menos dos funcionarios intervengan en la decisión a efectos de garantizar la debida utilización de tan extrema medida". ${ }^{59}$ Después del Decreto 2700 de 1991, se expidió la Ley 600 de 2000, que pretendió introducir algunos rasgos de adversarialidad, aunque mínimos; regula este instituto en el art. 301, en consonancia con el Decreto 2699 de 1991, sin que se produzcan mayores cambios. Estos sistemas con alguna tendencia inquisitiva, aun siendo mixtos, se caracterizaban, entre otras cosas, por el hecho de que la Fiscalía tenía amplísimas facultades judiciales, como la de determinar por sí y ante sí la detención preventiva de los sindicados, o la de declarar la preclusión de las investigaciones.

El sistema penal acusatorio se cristaliza con el Acto Legislativo 03 de 2002, en el que se introducen cambios constitucionales para permitir el paso al sistema penal oral y adversarial o acusatorio, que termina formalizándose en la Ley 906 de 2004. Entre las modificaciones, el art. 250, num. 2 de la Constitución quedó de la siguiente manera:

Art 250. En ejercicio de sus funciones la Fiscalía General de la Nación, deberá:

[...]

Sentencia de 22 de octubre de 1996 y Corte Suprema de Justicia-Sala de Casación Penal, Rad. 13.255, Sentencia de 23 de noviembre de 2000.

59 Corte Suprema de Justicia-Sala de Casación Penal, Rad. 9.579, Sentencia de 22 de octubre de 1996. 
Adelantar registros, allanamientos, incautaciones e interceptaciones de comunicaciones. En estos eventos el juez que ejerza las funciones de control de garantías efectuará el control posterior respectivo, a más tardar dentro de las treinta y seis (36) horas siguientes. ${ }^{60}$

Originalmente, el Acto Legislativo adicionaba "al solo efecto de determinar su validez". Sin embargo, esta parte final fue declarada inconstitucional, porque el juez no solo debe revisar su legalidad formal, sino también su legalidad material. ${ }^{61}$

Si bien es cierto que ahora la Fiscalía en su mayoría de funciones actúa como parte del proceso, en algunas actuaciones sigue revestida de autoridad judicial. La Corte Constitucional entiende que la Fiscalía tiene ciertas prevalencias para restringir el derecho de la intimidad, en esas tres actuaciones (registro y allanamientos, incautaciones e interceptaciones de comunicaciones) y luego de que se adelanten estas actividades, sí tendría un control posterior por parte de juez de garantías. ${ }^{62}$ Las demás actuaciones que impliquen una vulneración de derechos fundamentales requieren control

60 República de Colombia, Constitución Política de Colombia, modificada por: Congreso de la República. Acto Legislativo 03 de 2002. "Por medio del cual se modifican los artículos 15, 24, 28 y 250 de la Constitución Política de Colombia para enfrentar el terrorismo", publicado en el Diario Oficial n. ${ }^{\circ}$ 45.406, de 19 de diciembre de 2003.

61 Corte Constitucional, Sentencia C-092 de 2003.

62 Ídem. 
previo, en concordancia con el 246 del cPp vigente y del art. 250, num. 3 de la Constitución.

Se introduce en la Ley 906 una división de tareas entre el fiscal, el juez de control de garantías y el juez de conocimiento: el fiscal se encarga de acusar y allegar el material probatorio, el juez de control de garantías se revisa la legalidad del material probatorio, y el juez de conocimiento se ocupa de su valoración. ${ }^{63}$ Ahora bien, el art. 246 establece que se requiere el control previo de aquellas actuaciones que afecten derechos y garantías fundamentales que no se hayan nombrado en el capítulo "actuaciones que no requieren autorización judicial previa” (arts. 213 a 245). ${ }^{64}$

Si bien uno de los cambios más importante gracias al Acto Legislativo 03 de 2002 es la introducción del juez de control de garantías, es cierto que el fiscal en el proceso de Ley 906 está revestido de cierta autoridad judicial para ordenar a la Policía Judicial que realice la interceptación de comunicaciones, a diferencia del Decreto 2700 de 1991 y la Ley 600 de 2000, donde se requería una autorización judicial previa, que le correspondía diligenciar ante a la misma entidad. En el anterior estatuto orgánico de la Fiscalía, Decreto 2699 de 1991, síse tenía que hacer un control previo dependiendo de en qué momento tenía lugar, ya fuera por el fiscal, cuando

63 Ídem.

64 A pesar ello, dicho capítulo tiene un espectro mucho más amplio que las tres actuaciones que dice el art. 250 constitucional que requieran control posterior, salvo la búsqueda selectiva en bases de datos, por la Sentencia C-36 de 2007, y los exámenes que involucren al indiciado o al imputado, por la Sentencia C-334 de 2010, que requieren control previo. 
era por iniciativa por la Policía Judicial, o por la Dirección Nacional de Fiscalías, cuando era por iniciativa del fiscal delegado. En el actual Estatuto Orgánico, Ley 938 de 2004, se omitió dicho control previo interno.

\subsubsection{Descripción general del proceso penal vigente}

$\mathrm{Al}$ suceder un hecho jurídicamente relevante, se tiene la noticia criminis; después de que la Policía Judicial haya realizado los actos urgentes, esta le presenta un informe a la Fiscalía, la que asume conocimiento, según el art. 66 del cPr. Se adopta un programa metodológico de investigación, tal como lo señala el art. 207. En dicho programa se ordenan tres posibles clases de actividades: unas que no requieren autorización judicial, previstas en los artículos 213 y siguientes; otras que requieren control de legalidad posterior según el art. 237; y las que requieren control previo según los artículos 246 y siguientes. A partir de estas tres opciones se van conformando los elementos materiales probatorios y la evidencia testimonial potencial, y cuando el fiscal considera que tiene suficiente material probatorio que conlleve una inferencia razonable sobre los hechos que se estén investigando, solicita que se adelante la audiencia de imputación según los artículos 286 y siguientes, ante el juez de control de garantías, según el art. 154 num. 6, la que tiene por fin comunicarle a la persona que es imputada, e interrumpir la prescripción de la acción penal. ${ }^{65}$

65 Cfr., Ramírez Contreras, Luis Fernando. Las audiencias en el sistema penal acusatorio. 2. a ed. Editorial Leyer, Bogotá, 2007, pp. 25-28. 
Ante el juez de control de garantías se adelantarán las audiencias de control previo o posterior de las evidencias físicas y elementos materiales probatorios obtenidos durante la indagación e investigación. El control de legalidad, tanto previo como posterior, tiene como "propósito específico el de llevar a cabo la revisión formal y sustancial del procedimiento utilizado en la práctica de las citadas diligencias, esto es, verificar que se hayan respetado los parámetros constitucionales y legales establecidos para su autorización y realización, e igualmente, que la medida de intervención no haya desconocido garantías fundamentales (CP art. 250 у срP art. 39)". ${ }^{66}$ De igual forma, el juez de control de garantías tendrá competencia residual sobre aquello que no le fue asignado a otro juez, por lo que también se adelantan ante este otras actuaciones. ${ }^{67}$

Ya hecha la imputación y las audiencias preliminares que haya sido necesario practicar, el art. 175 ordena que el fiscal presente el escrito de acusación, y con él se fijará la fecha de audiencia de acusación. En ella, se acusará por los hechos jurídicamente relevantes, con una calificación del delito o delitos, y se hará un descubrimiento del material probatorio por parte del fiscal, acorde a los arts. 336 y siguientes. ${ }^{68}$

66 Corte Constitucional, Sentencia C-025 de 2009.

67 Ibíd., pp. 28-32. Otras actuaciones como las que señalan los artículos 84 (medidas cautelares sobre bienes susceptibles de comiso), 134 (medidas de protección de víctimas), 284 (pruebas anticipadas), 297 (solicitud de orden de captura), 306 (medida de aseguramiento), 317 (petición de libertad), 318 (solicitud de Revocatoria) y 327 (principio de oportunidad).

68 Ibíd., pp. 33-36. 
Hay que tener presente que el juzgamiento formalmente se inicia a partir de esta audiencia; antes de esta están las etapas de indagación e investigación en las que se desarrollan diligencias preliminares. ${ }^{69}$

Realizada la audiencia de acusación, se efectuará la audiencia preparatoria según los arts. 175 y 343. En esta audiencia, regulada principalmente por el art. 355 y siguientes, se harán observaciones sobre los elementos materiales probatorios descubiertos por la Fiscalía; habrá descubrimiento de los elementos probatorios de la defensa, se acordarán las estipulaciones que deseen las partes; se solicitarán los medios probatorios propuestos para practicar en el juicio oral. En este momento procesal se podrá solicitar la exclusión, rechazo o inadmisibilidad de las pruebas ilícitas, ilegales o impertinentes, y se decretarán las pruebas que hayan pasado el análisis de conducencia, pertinencia y utilidad por parte del juez, decisión contra la que se pueden interponer recursos de reposición y apelación. Es entonces esta la oportunidad final de enunciar, solicitar, decretar e impugnar sobre la introducción de resultados de interceptación de comunicaciones al juicio oral.

Al concluir la audiencia preparatoria se fija fecha y hora para desarrollar el juicio oral, según los arts. 175, 366 y siguientes; al finalizar este se anunciará el sentido del fallo y

69 Cfr. Montealegre Lynett, Eduardo y Bernal Cuéllar, Jaime El proceso penal. Estructura y garantías procesales. Tomo II. Universidad Externado de

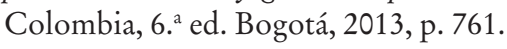


se dictará la sentencia de acuerdo con los arts. 446 y $447 . .^{70}$ Cuando el fallo quede en firme se hará una solicitud de incidente de reparación integral de perjuicios.

Ante estas providencias se puede interponer recurso de apelación, según lo previsto por los arts. 20 y 176 al 179A, donde resaltamos las causales del art. 177; resaltamos el inc. 1. num. 5 que lo prevé para la decisión de exclusión de la prueba, y el inc. 2 num. 4 que trata del control de legalidad del diligenciamiento de allanamiento y registro, retención de correspondencia, interceptación de comunicaciones o recuperación de información dejada al navegar por Internet.

Asimismo, encontramos que ante la sentencia de segunda instancia se puede interponer recurso de casación, donde cabría la causal de no haberse decretado la exclusión de la prueba, según el art. 180 y siguientes del Código, alegando error de derecho por falso juicio de legalidad. ${ }^{71}$ En algunos casos excepcionales se podría interponer acción de tutela contra providencia judicial por incurrir en "vías de hecho", es decir "aquellas actuaciones judiciales en las que el juez que decide un conflicto jurídico asume una conducta que contraría de manera evidente el ordenamiento jurídico vigente

70 Ramírez Contreras, Luis Fernando. Op. cit., pp. 38-40. Teniendo en cuenta las modificaciones de Ley.

71 Cfr., Corte Suprema de Justicia-Sala de Casación Penal, Rad. 29853, Sentencia de 20 de agosto de 2008. Esta dice: "el yerro se cristaliza cuando el fallador valora o aprecia un medio de prueba que desconoce alguna de esas ritualidades, o porque califica de ilegal [o ilícita] una que sí las satisface y por tanto es válida”. 
violando derechos fundamentales", ${ }^{72}$ y se podría presentar esta acción alegando un defecto fáctico ${ }^{73}$, positivo $^{74}$.

Hay que tener en cuenta que para que proceda la acción de tutela, aparte de los requisitos propios de esta, se requiere que la prueba por la cual se interpuso sea la única razón para de declarar la culpabilidad del procesado. ${ }^{75} \mathrm{El}$ juez de tutela no puede suplantar al juez de instancia; por lo tanto, solamente podrá estudiar si hubo una evidente irregularidad, y en lo que nos interesa, en la no aplicación de la regla de exclusión. ${ }^{76}$ Por tal razón, aunque la aplicación de la regla de exclusión es sobre pruebas, si la sentencia tiene como pilar fundamental dentro de la ratio decidendi una prueba ilícita o ilegal, al declarar su exclusión, se puede derrumbar toda la ratio, y necesariamente se tendrá que declarar el amparo, y con ello la nulidad del proceso desde la práctica de pruebas por desembocar en violación del principio de congruencia probatoria. $^{77}$

72 Corte Constitucional, Sentencia SU-159 de 2002.

73 Ídem. Esto es, "la aplicación del derecho sin contar con el apoyo de los hechos determinantes del supuesto legal a partir de pruebas válidas".

74 Ídem. Encontramos que hay dos dimensiones: uno negativo, que corresponde a cuando el juez no valora la prueba sin una razón valedera; y otro positivo, que es el punto de nuestro interés, el cual "se presenta generalmente cuando aprecia pruebas que no ha debido admitir ni valorar, porque, por ejemplo, fueron indebidamente recaudadas (art. $29 \mathrm{cN}$ )". Es decir, el defecto fáctico en su dimensión positiva consiste en la no aplicación de la regla de exclusión.

75 Ídem.

76 Corte Constitucional, Sentencia T-233 de 2007.

77 Cfr., Corte Constitucional, sentencias T-916 de 08 y T-233 de 2007, entre otras; y Corte Suprema de Justicia-Sala de Casación Penal, Rad. 24.679, Sentencia de 27 de julio de 2006: en esta no declara la nulidad del proceso por- 


\subsubsection{Descripción del proceso para desarrollar la interceptación de comunicaciones}

En el momento procesal donde la Fiscalía abre indagación preliminar tras la noticia de un delito, y junto con la Policía Judicial establece el programa metodológico en el que establece la forma como se va a adelantar la investigación, según se había señalado, la Fiscalía cuenta con tres vías para obtener material probatorio, entre las que encontramos las acciones que requieren control posterior por el juez de control de garantías. ${ }^{78}$ Una de las actividades que requieren control posterior es la interceptación de comunicaciones, para la que se necesitará primero una orden del fiscal a cargo de la investigación; en ese caso, el fiscal actúa en función de autoridad judicial. ${ }^{79}$ Dicha orden debe ser escrita, de acuerdo con el art. 235 del CPP, y debe fundamentarse en cuatro condiciones específicas:

1. Debe hacer referencia a una conducta delictiva por el cual se concentra la interceptación;

que había aún suficiente material probatorio para que el fallo quedara firme. En concreto, dice:

En efecto aun cuando se suprimiera el video como medio probatorio por su eventual ilicitud, la situación jurídica que se define en este fallo no sufriría modificación sustancial pues la reunión en la casa 39 de la Urbanización Colina Campestre de Yopal y la recepción en ella del dinero, son hechos demostrados plenamente con abundante prueba testimonial y aceptados por el mismo acusado. De tal modo que su eliminación en el proceso carece de la importancia que le atribuye la defensa.

78 Ramírez Contreras, Luis Fernando. Op. cit., p. 121.

79 Cfr., Corte Constitucional, Sentencia C-540 de 2011; y Montealegre Lynett, Eduardo y Bernal Cuéllar, Jaime. Tomo II. Op. cit., p. 281. 
2. Definir la persona por el cual recae la interceptación;

3. Especificar los números telefónicos; y

4. Definir el tiempo en que se desarrolla la interceptación. ${ }^{80}$

Con relación al último punto, una interceptación tendrá como plazo máximo seis meses, ${ }^{81}$ pero si la Fiscalía considera que es necesario prorrogarla, es exigido un control de legalidad previo; según la Sentencia C-131 de 2009, tras la modificación de la Ley 1142 de 2007, la prórroga sí requiere control previo. Después, regla que se dio por jurisprudencia constitucional, quedó incorporada directamente en el CPP gracias a la Ley 1453 de 2011.

Si bien el control posterior no tiene un capítulo específico destinado, lo encontramos en el art. 237. En su primer inciso dice:

Dentro de las veinticuatro (24) horas siguientes al recibimiento del informe de Policía Judicial sobre las diligencias de las órdenes de registro y allanamiento, retención de correspondencia, interceptación de comunicaciones o recuperación de información producto de la transmisión de datos a través de las redes de comunicaciones, el fiscal

80 Farfán Molina, Francisco. La interceptación de Comunicaciones telefónicas en el proceso penal y disciplinario. Ediciones Nueva Jurídica, Bogotá, 2008, pp. 39-43.

81 A pesar que el art. 235 dice que se tiene seis meses, el manual de procedimiento de la Fiscalía permite hasta tres meses. Cfr., Fiscalía General de la Nación. Manual de procedimientos de la Fiscalia en el sistema penal acusatorio. Fiscalía General de la Nación, Bogotá, 2009, p. 50. 
comparecerá ante el Juez de Control de Garantías, para que realice la audiencia de revisión de legalidad sobre lo actuado. ${ }^{82}$

Siendo así, encontramos que para hacer valer la interceptación de comunicaciones, se requiere control posterior por parte del juez de control de garantías para validar el acto de investigación, pero para que este posteriormente sea introducido al proceso penal tendrá que presentarse en la audiencia de acusación y se decidirá sobre su admisión o rechazo en la audiencia preparatoria. Teniendo en cuenta el momento procesal, el derecho del indiciado de estar presente en la audiencia de control posterior puede variar: cuando la interceptación se realiza después de la audiencia de imputación, el parágrafo del art. 237 ordena que se cite al imputado y a su defensor a la audiencia de control posterior. Pero si se realiza la interceptación antes de que se haga imputación, la Sentencia C-025 de 2009 (donde declara inexequible la palabra "solo", y declara exequible el inciso segundo del art. 237) considera lo siguiente:

[C]uando el indiciado tenga noticia de que en las diligencias practicadas en la etapa de indagación anterior a la formulación de la imputación, se está investigando su participación en la comisión de un hecho punible, el juez de control de garantías debe autorizarle su participación

82 Corte Constitucional, Sentencia C-025 de 2009. 
y la de su abogado en la audiencia posterior de control de legalidad de tales diligencias, si así lo solicita. ${ }^{83}$

Es decir, si se ordena una interceptación con anterioridad a la imputación, no se tiene el deber de citar al control posterior de legalidad al indiciado que no tiene conocimiento de la existencia de la indagación. Pero cuando un indiciado sabe que se adelanta una indagación en su contra, el juez debe autorizar su participación en las de control posterior. Si se ordena o se realiza la interceptación con posteridad a la imputación, el juez debe citar a la contraparte (Fiscalía y víctima o imputado) y su abogado a la audiencia de control posterior.

La decisión del juez de control de garantías sobre el control de legalidad y de constitucionalidad del material probatorio, en este caso de la interceptación de comunicaciones, debe estar sujeta a un juicio de proporcionalidad. Es decir, para tomar la decisión el juez debe revisar tanto la idoneidad, necesidad y proporcionalidad en estricto sentido ${ }^{84}$, y ante

83 Corte Constitucional, Sentencia C-025 de 2009; esta sentencia de constitucionalidad le da igual alcance para los arts. 242 (actuación de agentes encubiertos), 243 (entrega vigilada), 244 (búsqueda selectiva en bases de datos), y 245 (exámenes de ADN que involucren al indiciado o al imputado).

${ }^{84}$ Montealegre Lynett, Eduardo y Bernal Cuéllar, Jaime. Tomo II. Op. cit., pp. 288, 289; Cfr., Novoa Velásquez, Néstor Armando. Nulidades en el procedimiento penal. Actos procesales y acto prueba. Sistemas mixto inquisitivo y mixto acusatorio. Tomo I. Editorial Biblioteca Jurídica Diké, Bogotá, 2011, pp. 679-681; y Alexy, Robert. "Tres escritos sobre los derechos fundamentales y la teoría de los principios". Universidad Externado de Colombia, Bogotá, 2003; Cfr., CiDH. Caso Escher y otros v. Brasil. Sentencia del 6 de julio de 2009, párr. 129. 
ello revisar los principios propios del derecho vulnerado. ${ }^{85}$ En el caso de que la defensa participante se encuentre insatisfecha con la decisión del juez de control de garantías por el control de legalidad que se hizo sobre la interceptación, ya sea por violación de los requisitos formales o sustanciales, puede interponer recurso de apelación, o alegar la exclusión de esta en la audiencia preparatoria directamente ante el juez de conocimiento.

85 Corte Constitucional, Sentencia T-787 de 2004. Al momento de hacer el control de proporcionalidad en sentido estricto resulta necesario tener en cuenta los cinco principios que enumeró la Corte Constitucional para delimitar "lo público" de lo "privado":

El principio de libertad, según el cual, los datos personales de un individuo, sólo pueden ser registrados o divulgados con el consentimiento libre, previo, expreso o tácito del titular, a menos que el ordenamiento jurídico le imponga la obligación de relevar dicha información, en aras de cumplir un objetivo constitucionalmente legítimo. En este contexto, la obtención y divulgación de datos personales, sin la previa autorización del titular o en ausencia de un claro y preciso mandato legal, se consideran ilícitas. [2] El principio de finalidad, el cual se expresa en la exigencia de someter la recopilación y divulgación de datos, a la realización de una finalidad constitucionalmente legítima, lo que impide obligar a los ciudadanos a relevar datos íntimos su vida personal, sin un soporte en el Texto Constitucional que, por ejemplo, legitime la cesión de parte de su interioridad en beneficio de la comunidad. [...] De conformidad con [3] el principio de necesidad, la información personal que deba ser objeto de divulgación, se limita estrechamente a aquella que guarda relación de conexidad con la finalidad pretendida mediante su revelación. Así, queda prohibido el registro y la divulgación de datos que excedan el fin constitucionalmente legítimo. Adicionalmente, [4] el principio de veracidad, exige que los datos personales que se puedan divulgar correspondan a situaciones reales y, por lo mismo, se encuentra prohibida la divulgación de datos falsos o erróneos. Por último, [5] el principio de integridad, según el cual, la información que sea objeto de divulgación debe suministrarse de manera completa, impidiendo que se registre y divulgue datos parciales, incompletos o fraccionados. 
Posteriormente, el proceso penal tiene varias oportunidades y mecanismos para revisar el material probatorio: es revisado por el juez de conocimiento en el transcurso del proceso en primera instancia, en audiencia preparatoria y en juicio oral; por el superior jerárquico en caso de que se interpongan recursos de apelación, ya sea contra la decisión de admitir la prueba en la audiencia preparatoria, durante el juicio en primera y en segunda instancia si hay debate de exclusión probatoria, o en contra de la sentencia de primera instancia; también podrá ser revisado por la Corte Suprema de Justicia en recurso de casación; y eventualmente, en casos de acción de tutela contra sentencias, por jueces en primera y sengunda instancia y la Corte Constitucional en casos de acción de tutela contra sentencias.

\subsubsection{Comentarios sobre las actividades de inteligencia y contrainteligencia}

Se debe partir de que las actividades de inteligencia y contrainteligencia tienen una relación directa con la investigación criminal y con la protección de amenazas contra la seguridad nacional. Estas actividades generan una tensión entre el derecho a la intimidad, el principio de legalidad y el debido proceso, con la defensa y la seguridad nacional. Dentro de las diferentes actividades de inteligencia que se desarrollan, se encuentra el monitoreo del espectro electromagnético y la interceptación de comunicaciones.

Encontramos que se han venido adelantando diferentes intentos a través de los cuales se busca fortalecer el marco jurídico de las actividades de inteligencia. Entre ellos está 
la Ley 1288 de 2009, que fue declarada inexequible por la Sentencia C-913 de 2010, porque afectaba derechos fundamentales y ello hace que sea necesaria una Ley estatutaria. Se volvió a adelantar el proceso legislativo y se expidió la Ley 1621 de 2013, y seguidamente la Corte Constitucional revisó su constitucionalidad por medio de la Sentencia C-540 de 2012. Antes de esta Ley, la actividad de inteligencia se encontraba dispersa en diferentes normas, haciendo complejo su estudio. La Corte Constitucional, en la última sentencia citada, hace referencia a la Ley 57 de 1985 que regula el acceso a la información, como también a las Leyes 594 de 2000 y 850 de 2003, entre otras.

Enfocándonos en la Ley 1621 de 2013, encontramos que en el art. 2 define la función de inteligencia de la siguiente manera:

Artículo $2^{\circ}$. Definición de la función de inteligencia y contrainteligencia. La función de inteligencia y contrainteligencia es aquella que desarrollan los organismos especializados del Estado del orden nacional, utilizando medios humanos o técnicos para la recolección, procesamiento, análisis y difusión de información, con el objetivo de proteger los derechos humanos, prevenir y combatir amenazas internas o externas contra la vigencia del régimen democrático, el régimen constitucional y legal, la seguridad y la defensa nacional, y cumplir los demás fines enunciados en esta ley. 
La Sentencia C-540 de 2012, siguiendo a la Sentencia T-708 de 2008, "defin[e] la inteligencia como la recopilación y análisis de información relativa al sostenimiento de la seguridad general que debe estar circunscrita al respeto de los derechos fundamentales y al sistema de control de poderes". ${ }^{86}$ También es importante resaltar que esta función de recopilación y análisis de la información tiene como límite, diciéndolo expresamente el art. 4, el derecho internacional humanitario, el derecho internacional de los derechos humanos, la Constitución y la ley, y establece que solamente se ejercerá para tres fines:

86 Corte Constitucional, Sentencia C-540 de 2012; Cfr., Corte Constitucional, sentencias T-708 de 2008 y C-1011 de 2008. También Cfr., C-913 de 2010, donde dice:

De los anteriores conceptos (haciendo referencia a otros sistemas y al marco nacional) pueden destacarse, entre otros, los siguientes elementos comunes acerca de las labores de inteligencia y contrainteligencia: i) se trata de actividades de acopio, recopilación, clasificación y circulación de información relevante para el logro de objetivos relacionados con la seguridad del Estado y de sus ciudadanos; ii) el propósito de esas actividades y el de la información a que se ha hecho referencia es prevenir, controlar y neutralizar situaciones que pongan en peligro tales intereses legítimos, así como hacer posible la toma de decisiones estratégicas que permitan la defensa y/o avance de los mismos; iii) es inherente a estas actividades el elemento de la reserva o secreto de la información recaudada y de las decisiones que en ella se sustentan, dado que la libre circulación y el público conocimiento de las mismas podría ocasionar el fracaso de esas operaciones y de los objetivos perseguidos; iv) dado que se trata de detectar y prevenir posibles hechos ilícitos y/o actuaciones criminales, la información de inteligencia y contrainteligencia es normalmente recaudada y circulada sin el conocimiento, ni menos aún el consentimiento de las personas concernidas. 
a. Asegurar la consecución de los fines esenciales del Estado, la vigencia del régimen democrático, la integridad territorial, la soberanía, la seguridad y la defensa de la Nación;

b. Proteger las instituciones democráticas de la República, así como los derechos de las personas residentes en Colombia y de los ciudadanos colombianos en todo tiempo y lugar - en particular los derechos a la vida y la integridad personal - frente a amenazas tales como el terrorismo el crimen organizado, el narcotráfico, el secuestro, el tráfico de armas, municiones, explosivos y otros materiales relacionados, el lavado de activos, $\mathrm{y}$ otras amenazas similares; y

c. Proteger los recursos naturales y los intereses económicos de la Nación. ${ }^{87}$

Estas actividades de inteligencia y contrainteligencia tendrán que revisarse a la luz del test de proporcionalidad y sus subprincipios de idoneidad, necesidad y proporcionalidad, stricto sensu, dado que si bien son unas intromisiones a derechos fundamentales, el legislador consideró que estas van encaminadas al cumplimiento de unos fines legítimos, y por ello se reguló como una Ley Estatutaria. Es decir, las actuaciones de los organismos de inteligencia (se señalan las

87 Congreso de la República. Ley 1621 de 2013. "Por medio de la cual se expiden normas para fortalecer el Marco Jurídico que permite a los organismos que llevan a cabo actividades de inteligencia y contrainteligencia cumplir con su misión constitucional y legal, y se dictan otras disposiciones”, publicada en el Diario Oficial n. ${ }^{\circ} 48.764$ de 17 de abril de 2013, art. 4. 
dependencias de Fuerzas Militares, Policía Nacional, Unidad de Información y Análisis Financiero (UIAF) y aquellos organismos que sean facultados por la ley), como parte de la revisión de las actividades en relación de estas con los fines, tendrán que someterse a un test de proporcionalidad. ${ }^{88}$

Concentrándonos en nuestra materia, el art. 17 trata el monitoreo del espectro electromagnético e interceptación de comunicaciones. Se distingue el monitoreo de la interceptación, en cuanto el primero consiste en un rastreo de manera aleatoria e indiscriminada en el que se puede presentar captación incidental de comunicaciones sin que implique un seguimiento individual. La interceptación consiste precisamente en un seguimiento individual y concreto propio de la investigación penal donde se buscan elementos probatorios. En el caso de las interceptaciones se requiere estar en regla con el art. 15 de la Constitución, y por tanto es una facultad estricta que le asiste a la Fiscalía. ${ }^{89}$ Con relación a esto encontramos en el art. 43 de la Ley 1621 de 2013, más lo que señala la Corte Constitucional al estudiar este artículo, "deberá sujetarse a estos requerimientos mínimos para garantía del Estado constitucional de derecho y los derechos fundamentales", ${ }^{90}$ refiriéndose a los objetivos y fines que la Ley establece.

88 Ibíd., arts. 3 y 5.

89 Cfr., Corte Constitucional, Sentencia C-540 de 2012, en el apartado referente al art. 17 de la Ley 1621 de 2013.

90 Cfr., Corte Constitucional, Sentencia C-540 de 2012, en el apartado referente al art. 53 del proyecto de Ley., correspondiente al art. 43 de la Ley 1621 de 2013. 
A pesar de que se puede encontrar la distinción conceptual entre el monitoreo y la interceptación, hay casos en que las entidades de inteligencia, ocupadas en el monitoreo, pueden terminar realizando interceptaciones, ya que la distinción consiste en que la "captación incidental” es una revisión del espectro electromagnético, y la interceptación consiste en examinar comunicaciones individualizadas que se pueden adelantar dentro del espectro. El punto es que se puede llegar a desvirtuar que dichas injerencias sean captaciones incidentales en cuanto se demuestre que haya una serie de captaciones a propósito o bajo programa, lo que podría dar base para alegar y probar un seguimiento individual y concreto. ${ }^{91}$ Adicionalmente, el art. 44 hace más difícil hacer esta distinción en cuanto faculta a los organismos de inteligencia para solicitar a los operadores de servicios de telecomunicaciones información sobre teléfonos individualizados y datos técnicos de los suscriptores. Si bien es cierto el mismo artículo señala que las interceptaciones de comunicaciones se desarrollarán en regla al art. 15 constitucional y al CPP, los miembros de inteligencia tendrán de antemano la información sobre teléfonos individualizados y personas concretas.

Otro problema que se encuentra es la filtración de información a los medios de comunicación, como se estudia en la Sentencia T-708 de 2008. En este caso el accionante considera que si no se puede probar que hubo interceptación de

91 Ante esto, el primer caso, de los tres que se expondrán más adelante, hace visible precisamente esta distinción. 
comunicaciones, sino una captación incidental en función del monitoreo del espectro electromagnético, sí encuentra que estas interceptaciones pueden vulnerar el derecho a la intimidad, relacionado con el secreto profesional, en cuanto a la profesión de abogado. Ante esto precisamente, en el art. 33 de la Ley 1621 establece que la información, los documentos, y los elementos técnicos serán de reserva legal por treinta años, extensibles por quince años más. De igual forma, en el art. 17 íbidem establece que la información recolectada que no sea útil para los fines previstos debe ser destruida y no debe ser almacenada en bases de datos.

Con relación al valor probatorio de los informes de inteligencia, estos carecen de tal por su calidad de ser sometidos a reserva legal, según los arts. 33 y 35 , aunque puedan servir como criterio orientador de las investigaciones que pueda hacer la Fiscalía en la indagación e investigación, siempre y cuando se garantice la reserva de información, medios, métodos, fuentes e identidad de los funcionarios. Sin embargo, podrían servir como prueba para verificar las actuaciones de los organismos de inteligencia con respecto a sus fines y límites. ${ }^{92}$ Este punto es importante relacionarlo con el último inciso del art. 313 del Decreto 2700 de 1991, adicionado por la Ley 504 de 1999, que consagraba que “[e]n ningún caso los informes de la Policía Judicial y las versiones suministradas por informantes tendrán valor probatorio en el proceso".

92 Cfr., Corte Constitucional, Sentencia C-540 de 2012, referente del art. 35 . 
En este caso, explica la Corte Constitucional en la Sentencia C-392 de 2000 lo siguiente:

La mencionada disposición se ajusta plenamente a la Constitución, en la medida en que no le asigna valor probatorio a los mencionados informes y versiones, por tratarse de actuaciones extraprocesales no controvertidas por las personas a las cuales se podían oponer dentro del proceso.

$[\ldots]$

Sin embargo, lo anterior no obsta para que el funcionario judicial competente pueda, a partir de dichos informes, producir dentro del proceso la prueba que se requiera para establecer la realidad y veracidad de los hechos que son relevantes en éste, la cual naturalmente puede ser controvertida por el sindicado. Pero se anota que lo que dicho funcionario puede valorar es la prueba producida regularmente en el proceso, mas no los mencionados informes. ${ }^{93}$

Así entonces, era posible constituir el elemento material probatorio a partir de testimonio o peritaje de funcionarios de la Policía Judicial, abriendo la posibilidad de que estos fueran controvertidos; a la luz de la Corte Constitucional, los informes de la Policía Judicial no tienen valor probatorio

93 Corte Constitucional, Sentencia C-392 de 2000, referente al art. 50 de la Ley 504 de 1999, que adiciona el último inciso al art. 313 del Decreto 2700 de 1991. 
por no poderse contradecir. Sin embargo, dentro del marco de la Ley 1621 de 2013, por lo pronto, no sería posible constituir elementos probatorios con base en esos informes en cuanto la información que se entrega a la Fiscalía está bajo la condición de reserva legal sobre los diferentes puntos señalados; dicha reserva haría imposible contradecir el informe de los organismos de inteligencia.

Por lo expuesto, se entiende que los organismos de inteligencia y contrainteligencia podrán desarrollar monitoreo del espectro electromagnético y desarrollar captaciones incidentales; si el organismo de inteligencia considera que la información captada es importante y pueda dar información sobre una noticia criminis o como un criterio de orientación para alguna investigación, podrá solicitar información a los operadores de servicios de telecomunicaciones, con las debidas autorizaciones, sobre los teléfonos y los suscriptores. Sin embargo, considerando que no puede desarrollar interceptación de comunicaciones, podrá aportar información y/o documentos, como informes de inteligencia, a la Fiscalía, siempre que esta garantice su reserva en regla a los arts. 33 y 35. Este aporte a la Fiscalía no tendría ningún valor probatorio y solo puede ser utilizado para orientar la indagación. Claramente, la Fiscalía sí podrá adelantar u ordenar la interceptación de comunicación pertinente, y hacerla valer en juicio, siempre y cuando esté en regla con el proceso anteriormente descrito.

A pesar de esto, si se desea que la información o los documentos, generalmente informes de inteligencia, sean introducidos a un proceso penal, primero se debe analizar 
si cumplen con los fines y principios que los rigen, y luego se deben levantar las reservas por el presidente de la República, según el art. 33, parágrafo 1, haciendo que estos sean oponibles, y por tanto se dejaría de cumplir la condición del art. 34. La desclasificación debe ser tanto del documento como de la información, los medios, métodos, fuentes, y el funcionario del organismo de inteligencia por el cual la Fiscalía introducirá el documento al proceso, con el fin de que al momento del juicio se pueda contradecir la prueba. El levantamiento de reserva de todos estos permitiría a la defensa contradecir la prueba, y por tanto tendría validez. Aun así, si la Fiscalía considera que se afecta la seguridad del Estado, podrá decidir no descubrir la prueba según el art. 345, num. 5, del CPP vigente. De esta forma encontramos que los informes de las entidades de inteligencia, para ser aportados a un proceso judicial, tendrán que cumplir todos los requisitos para garantizar la contradicción de la prueba.

\subsubsection{Prueba ilícita, regla de exclusión y prueba derivada}

Es importante resaltar la diferencia entre la inadmisibilidad, el rechazo y la exclusión de pruebas: la inadmisibilidad se predica de aquellos medios de prueba que resultan impertinentes o inconducentes; ${ }^{94}$ el rechazo es "la manera de invalidar elementos de conocimiento probatorio por el incumpli-

94 Novoa Velásquez, Néstor Armando. Nulidades en el procedimiento penal. Actos procesales y acto prueba. Sistemas mixto inquisitivo y mixto acusatorio. Tomo II. Editorial Biblioteca Jurídica Diké, Bogotá, 2011, p. 1030. 
miento de normas relativas al descubrimiento probatorio"; 95 la exclusión se aplica a "aquellos elementos de conocimiento y las pruebas [ilícitas o] ilegales”. ${ }^{96}$ Por otra parte, se diferencia "prueba" que es aquella que se practica en juicio oral y público, donde los sujetos procesales puedan participar de esta, ${ }^{97}$ a lo anteriormente adquirido o compilado como "elementos materiales probatorios" y "evidencia física" 98 e información legalmente obtenida. Se ha debatido que la regla de exclusión del art. 23 del cpp habla de "prueba", en lugar de medios de prueba ofrecidos para que lleguen a ser prueba en el juicio, pero se debe entender que en el lenguaje diario o rápido esos términos se trastocan frecuentemente $\sin$ que se justifique derivar de allí consecuencias importantes.

Si revisamos el art. 212 del mismo Código encontramos que el fiscal puede rechazar los elementos materiales probatorios que hayan desconocido "los principios rectores y garantías procesales”. De igual forma, el art. 232 habla de la orden viciada por falta de los requisitos legales en temas de registro y allanamientos, y por ello también se excluye. Por tanto, cuando el art. 23 trae la palabra "prueba", hace referencia a su sentido amplio, donde abarca los elementos materiales probatorios, evidencias físicas, y medios de prue-

95 Ídem.

96 Cfr., ibíd., p. 1028.

${ }_{97}$ Cfr., Parra Quijano, Jairo. Manual de derecho probatorio. 17. a ed., Librería ediciones el profesional, Bogotá, 2009, p. 177.

98 Cfr., Corte Suprema de Justicia-Sala de Casación Penal, Sentencia Rad, 39.948, Auto en segunda instancia de 21 de noviembre de 2012. 
ba propiamente dicho dentro del proceso penal, haciendo que la regla de exclusión sea transversal a todo el proceso. ${ }^{99}$

Estas distinciones son importantes en cuanto la escuela alemana ha distinguido dos puntos con respecto a las prohibiciones probatorias: la "producción de evidencias", por una parte, donde se debe cumplir el procedimiento establecido buscando garantizar los derechos del investigado, y por otra parte, con posterioridad de la producción, se estudia el uso judicial que tendrán las evidencias en el razonamiento del juez. ${ }^{100}$

En el proceso de la Ley 906, el momento central para la solicitud y declaración de exclusión es la audiencia preparatoria, en la que se puede debatir la forma en que se produjeron los elementos probatorios y la evidencia testimonial ofrecida. Aquellos medios que llegan a la audiencia preparatoria, a menos que se encuentren con alguna ilegalidad o ilicitud, se decretarán para ser practicados en el juicio oral. Después de la práctica probatoria, ya con las pruebas propiamente dichas, se revisa cuál puede ser el uso judicial que tienen al momento de tomar una decisión. La regla de exclusión se enfoca en la forma en que se producen los elementos probatorios; si estos, después de practicados, tienen

99 Cfr., Daza González, Alfonso Evidencia ilegal, evidencia ilícita y regla de exclusión. En: Revista Derecho Penal Contemporáneo (n. $\left.{ }^{\circ} 27\right)$. ISSN: $1692-$ 168. Editorial Legis, Bogotá (abril-junio), 2009.

100 Cfr., Guerrero Peralta, Óscar Julián. Las probibiciones de prueba en el proceso penal colombiano. Anotaciones desde el derecho comparado. En: Beling, Ernst y otros. Las prohibiciones probatorias. Editorial Temis S. A, Bogotá, 2009, pp. 155, 156. 
algún uso judicial, al resultar excluidos se puede afectar la ratio de la sentencia. ${ }^{101}$ Siguiendo a la Corte Suprema de Justicia, "[e]l juicio de legalidad se relaciona con el proceso de formación de la prueba, con las normas que regulan la manera de producir e incorporar la prueba al proceso, con el principio de legalidad en materia probatoria y la observancia de los presupuestos y las formalidades exigidas para cada medio". ${ }^{102}$

Así las cosas, encontramos que la correcta producción probatoria está en cabeza de la Fiscalía en cuanto ella tiene el deber de revisar el cumplimiento del debido proceso, como también del juez de control de garantías, el juez de conocimiento, y el juez de segunda instancia cuando conoce de las apelaciones por la admisión, rechazo o exclusión de material probatorio en la audiencia preparatoria. Con relación al uso judicial, el primer control es del juez de conocimiento dado que es el primero en apreciar la prueba, tanto individual como conjuntamente con las demás pruebas; seguidamente están los controles por el recurso de apelación ante el superior, el recurso de casación ante la Corte Suprema de Justicia, y eventualmente por los jueces en la acción de tutela que puede llegar hasta la Corte Constitucional.

101 Cfr., ibíd., pp.155-157.

102 Corte Suprema de Justicia-Sala de Casación Penal, Rad. 29.853, Sentencia de 20 de agosto de 2008. 


\subsubsection{Prueba ilícita y regla de exclusión}

El art. 29 constitucional sanciona la violación del debido proceso y los derechos fundamentales, con la declaración de nulidad de pleno derecho de las pruebas así afectadas. ${ }^{103}$ Este tipo de prueba se conoce como ilícita. El profesor Jairo Parra Quijano resalta el concepto de Ada Pellegrini: "Por prueba ilícita en sentido estricto, indicaremos por tanto la prueba recogida infringiendo normas o principios colocados por la constitución, frecuentemente para protección de las libertades públicas y los derechos de la personalidad y de su manifestación como el derecho a la intimidad". ${ }^{104}$

Hay diferentes calificaciones de prueba, pero sobre aquella que se relaciona con el principio de licitud, encontramos los tres siguientes: primero, la "prueba ilícita, que como ya se dijo, viola derechos fundamentales, sea que esa violación se haya cometido para conseguir la fuente, o el medio probatorio. La prueba ilegal, es decir, aquella que viola una norma legal. Y la prueba irregular desde el punto de vista procesal" enfocandonos en las dos primeras. ${ }^{105} \mathrm{La}$

103 Cfr., Parra Quijano, Jairo. Op. cit., p. 24, citando a: Pellegrini, Ada. Revista de la asociación de ciencias penales de Costa Rica. Año 7, n. ${ }^{\circ}$ 10, septiembre de 1995. El profesor Parra Quijano la define de la siguiente manera: "La prueba ilícita es aquella que se obtiene violando derechos fundamentales de las personas, bien haya sido para lograr la fuente de prueba o bien para lograr el medio probatorio, y su proscripción es consecuencia de la posición preferente de los derechos fundamentales en el ordenamiento y de su afirmada condición de inviolables" (Parra Quijano, Jairo. Op. cit., p. 20).

104 Ibíd., p. 24, citando a: Pellegrini, Ada. Revista de la asociación de ciencias penales de Costa Rica. Año 7, n. ${ }^{\circ}$ 10, septiembre de 1995.

105 Ibíd., p. 23. Cfr., Corte Constitucional, Sentencia SU-159 de 2002. Hay que hacer la salvedad de que la Corte Constitucional en dicha sentencia hace la 
Corte Suprema de Justicia ha entendido la distinción entre prueba ilícita y prueba ilegal de la siguiente manera:

Se entiende por prueba ilícita la que se obtiene con vulneración de los derechos fundamentales de las personas, entre ellos la dignidad, el debido proceso, la intimidad, la no autoincriminación, la solidaridad íntima; y aquellas en cuya producción, práctica o aducción se somete a las personas a torturas, tratos crueles, inhumanos o degradantes, sea cual fuere el género o la especie de la prueba así obtenida.

$[\ldots]$

La prueba ilegal se genera cuando en su producción, práctica o aducción se incumplen los requisitos legales esenciales, caso en el cual debe ser excluida, como lo indica el artículo 29 Superior. ${ }^{106}$

Esta clasificación es importante dado que configura el supuesto de hecho de la regla de exclusión, y como regla, a

distinción entre prueba inconstitucional y prueba ilícita; posteriormente cambia a la calificación que conocemos entre prueba ilícita (constitucional) y prueba ilegal (ilícita).

106 Corte Suprema de Justicia-Sala de Casación Penal, Sentencia Rad. 31.073 , Sentencia de $1 .^{\circ}$ de julio de 2009. Estos párrafos se han venido repitiendo constantemente a lo largo de los diferentes procedimientos: en relación con el proceso Ley 906, encontramos la sentencia citada; en el proceso Ley 600, lo encontramos en la Corte Suprema de Justicia-Sala de Casación Penal, Sentencia Rad. 21.529, Sentencia de 7 de septiembre de 2006; y en relación con el proceso Decreto 2700 de 1991, en la Corte Suprema de Justicia-Sala de Casación Penal, Sentencia Rad. 18.451, Sentencia de 8 de julio de 2004, y Rad. 18103 del 2 de marzo de 2005. 
un supuesto de hecho procede una sanción. ${ }^{107}$ El supuesto de hecho, o la fuente de exclusión - como lo llama la jurisprudencia-, se basa precisamente en la anterior calificación de prueba ilícita y prueba ilegal, principalmente. La sanción consistirá, según el art. 29, en que la prueba obtenida por alguna de las dos fuentes se declarará como nula de pleno derecho. Esta se conoce como regla constitucional de exclusión, y ha tenido desarrollo en las diferentes áreas del derecho. ${ }^{108}$

La clasificación de prueba ilícita y prueba ilegal se ve reflejada en dos reglas de exclusión dentro del cPr. Lo referente a la prueba ilícita se ha desarrollado en el art. 23 del código vigente, que dice: "Toda prueba obtenida con violación de las garantías fundamentales será nula de pleno derecho, por lo que deberá excluirse de la actuación procesal”. Y con relación a la prueba ilegal, su exclusión la encontramos en los arts. 359 y 360 del mismo código. El último reza: "El juez excluirá la práctica o aducción de medios de prueba ilegales, incluyendo los que se han practicado, aducido o conseguido con violación de los requisitos formales previstos en este código". El desarrollo de la jurisprudencia gira a partir del art. 23 del CPP y este se relaciona con el art. 29 constitucional, pero no se deben dejar de lado los arts. 359 y 360 , donde se pueden encontrar elementos relacionados con la legalidad, admisibilidad, autenticidad, credibilidad y relevancia.

107 Cfr., Quinche Ramírez, Manuel Fernando. Op. cit., pp. 65, 66.

108 Cfr., Corte Constitucional, Sentencia su-159 de 2002. 
La exclusión del art. 23 tiene relación con los derechos y garantías fundamentales y por ello se encuentra dentro del Título preliminar de principios y garantías fundamentales. La exclusión del art. 360 se encuentra dentro Título del срр que regula la audiencia preparatoria; de tal manera, pareciera ser que esta exclusión solo sería aplicable en dicha audiencia, y pasada esta ya no se podría aplicar, en cuanto los momentos procesales son perentorios. Sin embargo, el art. 177, num. 5 establece que se concederá la apelación en el efecto suspensivo contra el auto que decide sobre la exclusión de una prueba del juicio oral; por lo tanto, también en el curso del juicio se puede proponer y decidir esa exclusión.

Retomando la prueba ilícita, el art. 29, inc. 5 constitucional dice "[e]s nula, de pleno derecho, la prueba obtenida con violación del debido proceso". ${ }^{109}$ En este inciso se entiende que debido proceso "no comprende exclusivamente las garantías enunciadas en el art. 29 de la Constitución sino todos los derechos constitucionales fundamentales" ${ }^{110}$ Por esta razón, el profesor Parra Quijano dice que hay una interpretación no solo formal, sino también material de la expresión

109 Hay que tener en cuenta que tanto la primera como la cuarta comisión de la Asamblea Constituyente trataron la nulidad por violación de derechos y garantías en la constitución, y en la Comisión Accidental para conciliar ambos textos se adicionó la nulidad de pleno derecho al establecer que "(i) la nulidad se genera no sólo cuando hay torturas o tratos inhumanos o degradantes, sino ante cualquier violación de los derechos y garantías establecidos en la Constitución y (ii) la nulidad no se predicaría solo de declaraciones, sino también de cualquier otro medio de prueba"; Cfr., Corte Constitucional, Sentencia SU159 de 2002. Citando a: Antecedentes del artículo 29 en la Asamblea Nacional Constituyente. Biblioteca de la Corte Constitucional, folio 190.

110 Corte Constitucional, Sentencia su-159 de 2002. 
“debido proceso". ${ }^{111}$ Relacionando esto con la calificación anteriormente dada, la prueba ilegal tiene que ver más con el debido proceso formal, mientras que la prueba ilícita se vincula con el debido proceso material o sustancial. ${ }^{112}$ Los efectos de esta distinción consisten en que la prueba ilegal puede ser ponderada con respecto a su vicio, y si se considera que este no es esencial puede no ser excluida, mientras que la prueba ilícita genera una exclusión automática. Cabe la ponderación solo con respecto a las pruebas derivadas. ${ }^{113}$

Generalmente, la nulidad de pleno derecho se decreta sobre las pruebas, no sobre el proceso, de manera que solo se excluye la prueba y el proceso sigue su curso. ${ }^{114}$ Sin embargo, la Sentencia C-591 de 2005 prevé que se decretará la nulidad de todo el proceso cuando para la obtención de la evidencia se cometan crímenes como tortura, desaparición forzada o ejecución extrajudicial, por ser crímenes de lesa humanidad imputables a agentes del Estado. ${ }^{115}$

111 Cfr., Parra Quijano, Jairo. Op. cit., p. 23.

112 Cfr., Corte Constitucional, Sentencia T-233 de 2007.

113 Cfr., Corte Suprema de Justicia-Sala de Casación Penal, Sentencia Rad. 31.073, Sentencia de 21 de julio de 2009.

114 Cfr., Corte Constitucional, sentencias T-916 de 2008, T-233 de 2007, C-210 de 2007, SU-159 de 2002, C-372 de 1997.

115 Cfr., Corte Constitucional, Sentencia C-591 de 2005. Ante este punto consideramos que hay yerro entre los delitos enlistados y el concepto de lesa humanidad, considerando que estos delitos se pueden cometer sin que sean crímenes de lesa humanidad, dado que para estos se requiere un criterio de sistematicidad o generalidad. Sin embargo, a pesar de lo que establece en la parte considerativa, el Resuelve de la Corte no repite que sean de lesa humanidad, sino que enlista los delitos. Cfr., Corte Constitucional, Sentencia C-210 de 2007. La Corte Suprema de Justicia-Sala de Casación Penal, Sentencia Rad. 
Se han venido estableciendo cinco supuestos para que proceda la regla de exclusión: ${ }^{116}$

\section{Cuando}

se está ante una ilegalidad que compromete el debido proceso, bien sea cuando se han afectado las reglas sustantivas que protegen la integridad del sistema judicial o que buscan impedir que se tomen decisiones arbitrarias, o bien sea cuando han sido desconocidas formalidades esenciales que aseguran la confiabilidad de la prueba y su valor para demostrar la verdad real dentro del proceso penal. ${ }^{117}$

De tal manera, "no toda irregularidad en el decreto, práctica y valoración probatoria, implica automáticamente afectación del debido proceso". ${ }^{118}$ Esto hace que el juez analice el alcance de la irregularidad, y si resulta o no necesaria su exclusión.

2. Relacionado con la distinción de prueba ilícita y prueba ilegal, se debe revisar el alcance del debido proceso, es decir, "si se refiere exclusivamente a las

33621 del 10 de marzo de 2010, aplicó dicha regla en un caso donde se relatan torturas cometidas por agentes de la Sijín; la Corte decide declarar la nulidad del proceso desde la resolución de apertura de investigación.

116 Cfr., Quinche Ramírez, Manuel Fernando. Derecho constitucional colombiano... Op. cit., p. 216.

117 Corte Constitucional, Sentencia su-159 de 2002.

118 Cfr., Corte Constitucional, Sentencia T-916 de 2008. 
reglas procesales o si también incluye las que regulan la limitación de cualquier derecho fundamental". ${ }^{119}$ La importancia radica en que en caso de una prueba ilegal, esta se pueda subsanar, y en el caso en que no se subsane conllevaría a una violación al debido proceso formal y con ello su exclusión. ${ }^{120}$

3. En el caso del debido proceso material,

la decisión de excluir una prueba incide no sólo en el respeto a las garantías de imparcialidad, debido proceso, y derecho de defensa, sino, además, en el goce efectivo de otros derechos constitucionales, tales como la vida, la integridad y libertad, protegidos por el legislador mediante la sanción de quienes violen el Código Penal. ${ }^{121}$

En este caso, simplemente no existe forma de subsanar la prueba y por tanto deberá ser excluida.

4. “[E]l mandato constitucional de exclusión de las pruebas obtenidas con violación al debido proceso exige que el funcionario judicial de manera expresa determine que la prueba viciada no puede continuar formando parte del expediente". ${ }^{122}$ Esto garantiza que el juez decida de fondo sobre la decisión de excluir

119 Corte Constitucional, Sentencia su-159 de 2002.

120 Cfr., Parra Quijano, Jairo. Op. cit., p. 23.

121 Corte Constitucional, Sentencia su-159 de 2002.

122 Ídem. 
la prueba, asegurando que no haya una exclusión probatoria arbitraria.

5. Finalmente, la Corte Constitucional en el Resuelve de la Sentencia C-591 de 2005, establece la regla de que si una prueba se consigue por medio de una tortura, una desaparición forzada o una ejecución extrajudicial, se declarará la nulidad de todo el proceso si se prueba que esta conducta le es imputable a un agente del Estado.

Por lo anterior, la regla de exclusión del art. 360 se enfoca principalmente en los dos primeros supuestos. ${ }^{123}$ Sin embargo, aquellas pruebas ilegales que tienen un alcance sobre un derecho fundamental pueden llegar a ser consideradas como pruebas ilícitas, y se genera su exclusión. Los supuestos del tercero al quinto tienen una relación directa con el art. 23 del CPP, lo cual genera su exclusión e incluso la nulidad de todo el proceso, tal como señala el último supuesto. Acorde con esto, podemos decir que la prueba ilegal y la prueba ilícita cumplen con dos estándares de prueba diferentes: el primero parte desde el debido proceso formal, muy relacionado con las reglas procesales; y el segundo vincula el debido proceso material con los derechos fundamentales, sin perder de vista que una violación grave al debido proceso formal puede

123 Este tipo de prueba es lo que Parra Quijano llama "prueba irregular", en cuanto que sí hay una violación de una norma estrictamente procesal, pero no tiene mayor alcance a la garantía del procesado. Cfr., Parra Quijano, Jairo. Op. cit., p. 23. 
llegar a afectar otros derechos, y por tanto también sería cobijado por el art. 23 de CPP.

La regla de exclusión termina siendo entonces una garantía de protección de derechos, al condicionar la producción probatoria; y en caso de que se haya practicado, se prohíbe su uso judicial. Los deberes que tiene el Estado con base en el art. 2 no se pueden convertir en una razón para cometer actos violatorios de los derechos humanos, negando sus propios pilares. ${ }^{124}$ La jurisprudencia considera que la regla de exclusión cumple estas funciones:

Nuestro ordenamiento jurídico acoge así, con éste régimen de exclusión de la prueba constitucionalmente ilícita, el cumplimiento de una función disuasiva, en relación con la conducta futura de las autoridades, especialmente de las de policía judicial, protectora en cuanto a la integridad del sistema constitucional y judicial, de garantía de los principios y reglas del Estado social de derecho, aseguradora de la confiabilidad y credibilidad del sistema probatorio y, eventualmente, reparadora de los perjuicios causados al procesado con una arbitrariedad"125 (negrillas originales del texto).

124 Cfr., Corte Suprema de Justicia-Sala de Casación Penal, Sentencia Rad. 33.621, Sentencia de 10 de marzo de 2010.

125 Corte Suprema de Justicia-Sala de Casación Penal, Sentencia Rad. 18.451, Sentencia de 8 de julio de 2004, citando a: Corte Constitucional, Sentencia SU-159 de 2002; Cfr., Parra Quijano, Jairo. Op. cit., p. 34. 
Encontramos que la regla de exclusión, por deber del Estado de proteger garantías fundamentales, permite su aplicación en cualquier momento procesal. ${ }^{126}$ En caso de que una decisión judicial se encuentre en apelación, casación, o tutela por vía de hecho, y termine excluyendo una prueba ilícita determinante para la decisión, como habíamos dicho antes, se declarará la nulidad del proceso hasta la práctica de pruebas por violación al principio de congruencia. ${ }^{127}$

\subsubsection{Prueba derivada y sus excepciones en la regla de exclusión}

Resulta necesario hacer una breve mención sobre la prueba derivada teniendo en cuenta que a partir de una prueba ilícita se pueden generar muchas otras en el transcurso de la investigación penal. Las pruebas derivadas de las que se alega exclusión son aquellas que si bien son legales según la forma de producción, se basan en datos obtenidos por una primera prueba ilícita, o prueba base, donde hay una relación de causa-efecto entre la prueba base y la prueba derivada; haciendo analogía con un árbol, el tronco sería la prueba base, y las ramificaciones y sus frutos serían las pruebas derivadas. Cuando la prueba base es ilícita o ilegal termina afectando la relación causal de las pruebas derivadas, de tal manera que "al restarle mérito a la prueba ilegalmente obtenida afecta a aquellas pruebas que si bien son en sí mismas legales, no obstante están basadas en datos conseguidos por aquella prueba

126 Cfr., Corte Constitucional, Sentencia C-591 de 2005.

127 Cfr., ibíd., n. 96, 97. 
ilegal, llegándose a concluir que tampoco esas pruebas legales pueden ser admitidas”. ${ }^{128}$ En la analogía, la prueba ilícita envenena el árbol y con ello su fruto, de ahí su nombre: teoría de los frutos del árbol envenenado. Acorde con lo anterior, el art. 23, inciso segundo, ordena que la prueba derivada también sea excluida del expediente: "Igual tratamiento recibirán las pruebas que sean consecuencia de las pruebas excluidas, o las que solo puedan explicarse en razón de su existencia”.

Sin embargo, la jurisprudencia norteamericana, principalmente, ha desarrollado diferentes excepciones para su aplicación. Entre esas el CPP ha tomado tres que señala el art. 455: “Art. 455. Nulidad Derivada de la prueba ilícita. Para los efectos del artículo 23 se deben considerar, al respecto, los siguientes criterios: el vínculo atenuado, la fuente independiente, el descubrimiento inevitable y los demás que establezca la ley".

Podemos entender la fuente independiente como "aquella que no tiene conexión causal con la prueba ilícita original, por lo cual, si al conocimiento de los hechos se llega por una prueba lícita sin relación causal con la ilícita que trata sobre los mismos hechos, entonces aquella prueba lícita no es alcanzada por la regla de exclusión”. ${ }^{129}$ En otras palabras,

128 Parra Quijano, Jairo. Op. cit., p. 33.

129 Corte Suprema de Justicia-Sala de Casación Penal, Rad. 23.284, Sentencia de 5 de octubre de 2006, citando a: Jauchen, Eduardo. Tratado de la prueba en materia penal. Editorial Rubinzal-Culzoni. Buenos Aires, 2004, p. 646. 
la prueba derivada no tiene ninguna relación causal con la prueba ilícita, y por tanto esta no sería excluida. ${ }^{130}$

El descubrimiento inevitable consiste en que "cuando, dadas las circunstancias, a pesar de la ilegalidad, es viable deducir sin duda que la prueba hubiera sido obtenida lo mismo por otro medio legítimo". ${ }^{131}$ Se ha venido entendiendo esta como una extensión de la fuente independiente, como lo ha entendido la Suprema Corte de Estados Unidos: “[d]ado que la evidencia viciada hubiera sido admisible si era efectivamente descubierta a través de una fuente independiente, debería ser admisible si hubiese sido descubierta en forma inevitable"132. Sin embargo, como señala Guerrero Peralta, esta excepción ha tenido críticas dado que se discuten temas como qué tanto tiempo transcurriría para el descubrimiento de la prueba y realmente qué tan inevitable sería el descubrimiento, como se planteó en el caso norteamericano Nix vs. Williams. ${ }^{133}$

Ante el vínculo atenuado, este "se ha entendido que si el nexo existente entre la prueba ilícita y la derivada es tenue, entonces la segunda es admisible atendiendo al principio de la buena fe, como quiera que el vínculo entre ambas

130 Cfr., Guerrero Peralta, Óscar Julián. Institutos probatorios del nuevo proceso penal. Ediciones Nueva Jurídica. 1. ${ }^{a}$ ed., Bogotá, 2009, pp. 257-262. Vale la pena comentar que si no tiene ninguna relación causal, la prueba tampoco podría ser derivada.

131 Corte Suprema de Justicia-Sala de Casación Penal, Rad. 23.284, Sentencia de 5 de octubre de 2006.

132 Guerrero Peralta, Óscar Julián. Institutos probatorios... Op. cit., p. 264, citando a: Murray vs. United States 487 U.S. 539, 1988.

133 Cfr., ibíd., p. 267-272. 
pruebas resulta ser tan tenue que casi se diluye el nexo de causalidad". ${ }^{134}$ Si bien esta excepción se desarrolla principalmente en la jurisprudencia americana, deja muchos vacíos. El problema principalmente consiste en no tener claridad de cómo se atenúa dicha prueba según nuestras propias reglas. En nuestra percepción, vemos que el mejor ejemplo del vínculo atenuado es la utilización de la información obtenida por entidades de inteligencia; por ejemplo, mediante interceptaciones de comunicaciones no desarrolladas estrictamente dentro de los parámetros legales, si bien no es posible usarla en el proceso penal, sí puede ser usada como criterio orientador de una investigación penal, de manera que las informaciones derivadas y evidencia no necesariamente se vinculan con el origen irregular.

En el caso hipotético de que a una prueba aparentemente ilícita se le logre probar alguna de estas excepciones, la prueba deberá ser admitida dentro del proceso judicial. Pero a pesar del desarrollo legal, jurisprudencial y doctrinal, no resulta fácil encontrar ejemplos prácticos, por lo que a nuestro modo de ver, para explicar el vínculo atenuado es útil el de la información obtenida por las entidades de inteligencia, pero esta no se lleva ordinariamente al juicio.

134 Corte Suprema de Justicia-Sala de Casación Penal, Rad. 23.284, Sentencia de 5 de octubre de 2006, citando a: Corte Constitucional, Sentencia C-591 de 2005. 


\section{Conclusiones: aplicación de lo expuesto en los tres casos}

En resumen, encontramos que el modelo de Estado termina por defender la forma de un proceso y de un procedimiento judicial. En Colombia, por ser un Estado social de derecho, el ordenamiento incluye la dignidad humana como un pilar fundamental. La dignidad humana no se puede entender de manera aislada, sino que se estudia en relación con otros derechos humanos que permiten su manifestación, como es el caso del derecho a la intimidad. Este derecho no solo permite la tranquilidad de poderse manifestar sin una intervención no consentida, sino que además protege la relación entre personas y grupos. La manifestación de poder reunirse y comunicarse entre personas o grupos sin tener ninguna injerencia como regla general es un aspecto básico para el desarrollo de la democracia.

Pero por otra parte, el Estado también tiene el deber de perseguir los delitos, como una manifestación del art. 2 constitucional; por tal razón, hay momentos donde resulta necesario realizar injerencias en la privacidad de la persona, como es el caso de las interceptaciones de comunicaciones. Si bien es una injerencia al derecho a la intimidad, dicha excepción se encuentra regulada constitucional y legalmente, exigiéndose autorización judicial para hacerla. Al considerar que se requiere autorización judicial y que dicha autorización debe estar reglada por la Constitución y la Ley, se termina relacionando con el debido proceso, tanto material como formal. Solo a partir del cumplimiento de los ritos tal 
como lo establecen el CPP y las reglamentaciones propias de la Fiscalía, podrá darse una interceptación de comunicaciones lícitamente.

En el caso en que se realice sin autorización, por más loable que sea la razón, dicha prueba se considerará ilícita y por tanto deberá declararse su exclusión del proceso, así como también las pruebas derivadas de esta, salvo las tres excepciones para evaluar hasta dónde se extiende la ilicitud. La regla de exclusión es una garantía procesal para la protección de los derechos humanos en cuanto condiciona la producción probatoria y su uso judicial, y es aplicable en cualquier momento procesal, pudiendo emplear los diferentes recursos y mecanismos legales y constitucionales. Esa regla, al usarse en el proceso, si bien recae principalmente sobre la prueba, puede llevar a su nulidad cuando: primero, al excluir la prueba de una sentencia que haya sido esencial para establecer la condena, esta se vuelve insostenible, y por tanto se declara la nulidad hasta el momento de la práctica probatoria por violación al principio de congruencia probatoria; o segundo, siendo el supuesto más grave, si la prueba se obtuvo a partir de una tortura, desaparición forzada o ejecución extrajudicial, se declara la nulidad total de proceso y necesariamente se cambia el juez que haya tenido conocimiento.

Sin embargo, es interesante ver cómo la Fiscalía, a pesar de que se haya pasado de un sistema mixto con rasgos inquisitivos a otro con preponderancia acusatoria, necesitaba antes la autorización previa de otro funcionario para desarrollar la interceptación, ya fuera por el Fiscal delegado o 
por la Dirección Nacional de la Fiscalía, aunque fuera dentro de la misma entidad; sorpresivamente, al pasar a un sistema acusatorio no se requiere autorización previa para la primera orden sino que se hace un revisión posterior a la injerencia.

De igual forma, resulta llamativo ver la regulación de la actividad de inteligencia, que le permite monitorear el espectro electromagnético y adelantar captaciones incidentales; aunque estas captaciones son lícitas, y por regla general no tienen valor probatorio, siguen siendo una injerencia a la intimidad personal. Pero en los tres casos expuestos encontramos que estas fueron utilizadas en procesos judiciales y fueron claves para la condena de los procesados, claramente antes de la Ley 1621 de 2013.

1. En el caso de Juan Carlos Castillo las pruebas obtenidas por la RIME 4 son excluidas, y se usan las interceptaciones del cTr. A pesar de ello es importante resaltar que el Ejército sí tuvo la capacidad de adelantar interceptaciones de comunicaciones en cuanto su armamento estaba siendo vendido a otros sujetos de conflicto armado y bandas delincuenciales. De igual forma, considera que es un buen caso para explicar el "vínculo atenuado", puesto que aunque a la luz del Tribunal Superior de Bogotá son injerencias indebidas, por mandato legal estas sí pueden ayudar a orientar la investigación penal. Es importante resaltar que a pesar de que se pudo llegar a la condena del señor Castillo, la investigación presentó varios inconvenientes puesto que el CTI tuvo que modificar 
su plan de investigación al encontrar que las líneas ya estaban siendo interceptadas por la RIME 4, y cuando solicitó la interceptación de líneas diferentes también se encontró que algunas ya lo estaban. A pesar de su exclusión probatoria, tanto la investigación del CTI como de la RIME 4, contenían la misma información, solamente que el primero tuvo mayor desgaste mientras readaptaba su estrategia de investigación.

2. En el caso de la masacre de Macayepo, la sipol captó la conversación de Álvaro García Romero y Joaquín García Rodríguez, siendo así la prueba fundamental por la cual se demuestra la responsabilidad de Morris Taboada y García Romero. Si bien el análisis que plantea la Corte Suprema de Justicia tiene sustento en la sentencia de la Corte Constitucional, por lo cual se estudia el último inciso del art. 313 del Decreto 2700 de 1991, se cumplió el principio de contradicción y satisface los requisitos de relevancia y credibilidad, pero no satisface el criterio constitucional de que solamente se pueden hacer injerencias a la intimidad por autorización judicial. Es decir, si la prueba se observa desde el punto de vista de la prueba ilegal, esta cumple el estándar, pero desde el punto de vista de la prueba ilícita no lo cumple. También resaltamos que si hubiera estado rigiendo la Ley 1621 de 2013 para la fecha de los hechos, no tendrían ningún valor probatorio, al menos que se levantaran las reservas legales. 
3. En el caso de la toma del Palacio de Justicia, las captaciones incidentales por radioaficionados y aportadas por periodistas de Radio Todelar, sí hay varios cuestionamientos, siguiendo el salvamento de voto. Desde el enfoque de la prueba ilegal, hay dudas con respecto a la credibilidad, así como algunas divergencias al contradecirse los autores de estas. Desde la prueba ilícita, hay una contradicción entre lo que plantea la parte considerativa de la sentencia al decir que es una actitud loable de los ciudadanos, y el precedente de la Corte Constitucional en el sentido de que en ningún caso, por más buena intención que se tenga, podrán ser admitidas las injerencias ilícitas en las comunicaciones; a esto se le suma el salvamento de voto, que con respecto al señor Montaña, encuentra creíble la intención ilegal de interceptar las comunicaciones de los miembros del Ejército, dado que la frecuencia en la que ellos se comunicaban estaba por fuera de los rangos permitidos según lo reglamentado por el Ministerio de Comunicaciones para los radioaficionados y uso civil. De tal manera, pareciera que las interceptaciones no cumplen con los estándares de prueba, tanto de la prueba ilegal como de la prueba ilícita.

Encontramos una tensión entre las captaciones de organismos de inteligencia y de interceptaciones por terceros usadas como prueba en los procesos judiciales, contra la regla de 
exclusión del art. 23 del cPP en concordancia con el derecho a la intimidad. Es innegable la importancia de estas interceptaciones y captaciones para demostrar la responsabilidad penal, y más aún cuando son casos que están relacionados con el armamento de guerrillas o paramilitares, o una masacre contra la población civil, o la toma al Palacio de Justicia. Estas captaciones incidentales, ya sea por los miembros de inteligencia o por particulares, como sucedió en la toma del Palacio, van en contra de la regla constitucional de que estas injerencias requieren orden de la Fiscalía, entendida como una autoridad judicial, y aun así, a la luz del cPp vigente, se requeriría control posterior. Así, encontramos que si bien es una actividad legal en cuanto es permitida por una Ley - y con ello podría argumentarse que a la luz del estándar de la legalidad es factible-, es posible que a la luz de los mandamientos constitucionales pueda haber una tensión y por tanto el punto de debate está en si estas actividades pueden llegar a ser constitucionales o lícitas. 